\title{
RTT109 AND FUN30 PROTEINS MEDIATE EPIGENETIC REGULATION OF THE DNA DAMAGE RESPONSE PATHWAY IN C. ALBICANS
}

\author{
Pramita Garai ${ }^{\S}$, Prashant Kumar Maurya ${ }^{\S}$, Himanshu Bhatt, Aarti Goyal, Sakshi \\ Dewasthale, Meghna Gupta ${ }^{1}$, Dominic Thangminlen Haokip ${ }^{2}$ and Rohini Muthuswami ${ }^{\$}$ \\ Chromatin Remodelling Laboratory, School of Life Sciences, JNU, New Delhi \\ 110067
}

\$ Corresponding Author: Rohini Muthuswami, Room \# 333, School of Life Sciences, JNU, New Delhi 110067. Phone number + 9111 26704154; Email: rohini_m@mail.jnu.ac.in

${ }^{\S}$ Equal First Authors: Pramita Garai and Prashant Kumar Maurya contributed equally to this work.

${ }^{1}$. Present Address: Department of Biochemistry and Biophysics, University of California, San Francisco, USA.

2. Present Address: Department of Botany, United College, Chandel, Manipur

Running title: Epigenetic regulation of DNA damage response

Keywords: Rtt109, Fun30, DNA damage response, Epigenetics 


\section{ABSTRACT}

Fun30, an ATP-dependent chromatin remodeller, from S. cerevisiae mediates both regulation of gene expression as well as DNA damage response/repair. In this paper, we have characterized the biochemical and physiological function of Fun30 from the opportunistic fungi, C. albicans. Biochemically, the protein shows DNA-stimulated ATPase activity. Physiologically, the protein co-regulates transcription of RTT109, TEL1, MEC1, and SNF2-genes that encode for proteins involved in DNA damage response and repair pathway. The expression of FUN30, in turn, is regulated by histone H3 acetylation catalysed by Rtt109 encoded by RTT109. The RTT109Hz/FUN30Hz mutant strain shows sensitivity to oxidative stress and resistance to MMS as compared to the wild type strain. Quantitative PCR showed that the sensitivity to oxidative stress results from downregulation of $M E C 1, R A D 9, M R C 1$ and RAD5 expression; ChIP experiments showed Fun30 but not $\mathrm{H} 3 \mathrm{ac}$ regulates the expression of these genes in response to oxidative stress. In contrast, on treatment with MMS, the expression of $R A D 9$ is upregulated and this upregulation is co-regulated by both Fun30 and H3 acetylation catalysed by Rtt109. Thus, Fun30 and H3 acetylation mediate the response of the fungal cell to genotoxic agents in C. albicans by regulating the expression of DNA damage response and repair pathway genes. 


\section{INTRODUCTION}

The ATP-dependent chromatin remodelling proteins modulate gene expression as well as mediate DNA damage response/repair by using the energy released from ATP hydrolysis (1). Though classified as helicases and possessing the seven conserved helicase motifs, these proteins do not possess the canonical helicase activity $(2,3)$. Instead, these proteins use the energy stored in ATP to reposition, evict, or slide nucleosomes (4). In addition, they can also mediate histone variant exchange (5).

The ATP-dependent chromatin remodelling proteins are classified into 24 subfamilies of which the Et11 sub-family comprises of Et11 in mouse, SMARCAD1 in human, Fun30 in S. cerevisiae, and Fft1, Fft2, Fft3 in S. pombe (2). All the members of the subfamily have been shown to mediate DNA end resection during double-strand break repair, thus, indicating that these proteins are involved in the repair process $(6,7)$. Studies have also shown that these proteins are required for maintaining the chromatin structure at heterochromatic loci $(8,9)$. Biochemical studies have shown that the Fun30 from $S$. cerevisiae is a homodimer possessing DNA-stimulated ATPase activity (10). These studies have also shown that the purified protein can mediate nucleosome sliding as well as histone variant exchange; however, the efficiency in mediating histone variant exchange is greater than nucleosome sliding (10). The protein has not yet been characterized in C. albicans.

In addition to ATP-dependent chromatin remodelling proteins, histone modifying enzymes have also been shown to play a role in DNA repair. Rtt109 is a B-type histone acetyltransferase specific to yeast and fungi (11). Studies have shown that the protein acetylates histone $\mathrm{H} 3$ at $\mathrm{K} 56, \mathrm{~K} 9$, and $\mathrm{K} 27$ (12). The H3K56ac modification is associated with DNA damage response both in S. cerevisiae and in C. albicans $(13,14)$. This modification has been recently identified in mammalian cells too where p300 has been shown 
to mediate the acetylation at K56 position of histone H3 (15). Studies have shown that Rtt109 and p300 do not share sequence homology but do share structural similarity (16). As both Rtt109 and Fun30 are involved in DNA repair, therefore, in this paper we seek to ask whether there is any crosstalk between Fun30 and Rtt109 in C. albicans. $C$. albicans is an opportunistic pathogen causing candidiasis in immuno-compromised patients. The organism is an intracellular pathogen and the host cell combats the infection by generating ROS that causes DNA damage. Thus, $C$. albicans has evolved robust mechanisms to repair the damaged DNA thereby ensuring genomic stability (17). As stated earlier, the role of Rtt109 but not of Fun30 has been delineated in C. albicans (14). Rtt109 in $C$. albicans has been linked to pathogenesis; the cells lacking Rtt109 were found to be sensitive to genotoxic agents like camptothecin (CPT) and methyl methane sulfonate (MMS) indicating the role of the histone acetyltransferase in DNA damage response/repair (14). Recently, we have shown that Rtt109 mediated acetylation of $\mathrm{H} 3$ regulates the expression of genes involved in GPI anchor biosynthesis and in ergosterol biosynthesis (18). However, the crosstalk between Rtt109 and Fun30 has not yet been investigated.

In this paper we have characterized the biochemical and functional activities of Fun30 from C. albicans. We show that Fun30 regulates the expression of Rtt109 and in turn, Rtt109 regulates the expression of Fun30 via $\mathrm{H} 3$ acetylation (H3ac). Fun30 and H3ac are needed for the expression TEL1 and MECl encoding for the sensor kinases, Tel1 and Mec1 respectively. Finally, we show that Fun30 regulates the expression of Rad9, a cell cycle checkpoint protein, and Rad5, an ATP-dependent chromatin remodelling protein, in response to genotoxic stress, thus, modulating the DNA damage response pathway on induction of DNA damage. 


\section{RESULTS}

\section{The orf19.6291 encodes for Fun30, a member of the ATP-dependent chromatin}

remodelling protein family: C. albicans orf19.6291 is an uncharacterized protein annotated as Fun30 in the Candida Genome database (19). Phylogenetic analysis showed that orf19.6291 is closely related to Fun30 from S. cerevisiae (Supplementary Fig. 1A). Further, bootstrap values suggest that the orf19.6291 evolved along with Fft3, Fft2, SMARCAD1 and Etl1 (Supplementary Fig. 1A). Sequence analysis showed that orf19.6291 contained the conserved helicase motifs as well as CUE motif (Supplementary Figs. 1B and 2). The CUE motif that has been shown to recognize and bind to monoubiquitinated proteins (20) is present in the N-terminus of Fun30 in case of $S$. cerevisiae. However, the CUE motif in orf19.6291, as in the case of Fft2, is present between the subdomains of the helicase motifs (Supplementary Fig. 1B). Based on these analyses, it was concluded that orf19.6291 encodes for Fun30 in C. albicans.

Fun30 localizes to the nucleus: To understand the localization of Fun30 in $C$. albicans, one of the alleles of FUN30 in SN152 strain was myc-tagged at the C-terminus as explained in the Materials and Methods section. This strain is, hereinafter, referred as FUN30myc. Using anti-myc antibody, the localization of the protein was found to be predominantly in the nucleus (Supplementary Fig. 1C).

\section{Fun30 in C. albicans is a DNA-stimulated ATPase with fork DNA being the} optimal effector: To biochemically characterize Fun30 from C. albicans we attempted to purify the full-length protein by overexpressing it in E. coli. However, the yield of the protein was not sufficient to perform biochemical assays. Therefore, a truncated version of the protein lacking the $\mathrm{N}$-terminus from amino acids 1 to 512 ( $\Delta \mathrm{NFun} 30)$ was cloned and overexpressed in E. coli (Supplementary Fig. 1D and Fig. 1A). The purified protein showed DNA-independent activity like $S$. cerevisiae Fun30 (Fig. 1B). The ATPase activity was 
stimulated $~ 1.5$ fold in the presence of the $500 \mathrm{nM}$ fork DNA while other DNA molecules did not yield any significant stimulation (Fig. 1B). The $\mathrm{K}_{\mathrm{M}}$ for the interaction with fork DNA was calculated to be $0.06 \pm 0.007 \mu \mathrm{M}$ (Fig. 1C). The binding parameters, using fluorescence spectroscopy, for the interaction of ATP and DNA with the protein were calculated both in the absence and presence of the other ligand. The binding studies showed that the interaction of fork DNA with the protein was similar both in the absence and presence of saturating concentration $(60 \mu \mathrm{M})$ of ATP (Fig. 1D and F). In contrast, the interaction of ATP was 2fold weaker in the presence of saturating concentration $(6 \mu \mathrm{M})$ of fork DNA (Fig. 1E and F).

\section{Fun30 regulates the expression of RTT109, SNF2, TEL1, and MEC1 in $C$.}

albicans: To understand the physiological role of Fun30 in C. albicans a heterozygote mutant was created where one copy of the gene was deleted in SN152 as well as in BWP17 strain of C. albicans. In case of SN152, we used the FUN30myc strain where one copy of FUN30 was fused with myc to encode Fun30myc protein.

The heterozygous mutant was confirmed using PCR and HIS1 cassette specific primers in both FUN30myc and BWP17 strains (Supplementary Fig. 3A-C). Hereinafter, the heterozygous mutant, FUN30/fun30, is referred as FUN30mycHz if made in FUN30myc background and as $F U N 3 O H z$ if made in BWP17 background. We ensured that in FUN30mycHz strain, the copy lacking the myc tag was deleted to create the $\mathrm{FUN3OmycHz}$ mutant. Quantitative PCR (qPCR) showed that the expression of FUN30 was downregulated in the heterozygote mutant both in FUN30myc and BWP17 strains (Fig. 2A and B). We were unable to create homozygous null mutant, fun30/fun30. We tried creating homozygous null mutant using ARG4 marker both in FUN30myc and BWP17 strains. We made at least 6 attempts for each strain screening more than 120 colonies, but we did not get any null mutant. Supplementary Fig. 3D shows the gel picture of one such attempt made in $\mathrm{FUN} 30 \mathrm{~Hz}$ strain. We also tried to make a conditional null mutant using MET3 promoter in BWP17 strain. We 
made 4 attempts and screened more than 20 colonies. Once again, we were unsuccessful. However, both copies could be deleted when FUN30 was ectopically expressed in BWP17 (Supplementary Fig. 3E and F). For this experiment, FUN30 was cloned into pACT1 vector and overexpressed in BWP17 using URA3 as selection marker. One copy of FUN30 was deleted using HIS1 specific cassette and the other copy was deleted using ARG4 specific cassette. As FUN30myc possesses URA3, this experiment could not be performed in this strain.

Previously, we had shown that in mammalian cells the DNA damage response pathway is transcriptionally regulated by ATP-dependent chromatin remodelling proteins (21-23). Fun30, an ATP-dependent chromatin remodelling protein, mediates not only DNA end resection but also modulates transcriptional co-regulation $(7,24-26)$. Therefore, we investigated whether Fun30 regulates genes involved in the DNA damage response pathway in C. albicans. Specifically, we sought to investigate the expression of Rtt109 that acetylates H3 at K56 and other positions, Tel1 and Mec1 that are functional homologs of ATM and ATR, and Snf2 that is the functional homolog of BRG1. Tel1 and Mec1, like ATM and ATR, are kinases that are activated on DNA damage and transduce the signal to downstream effectors via phosphorylation (27). In mammalian cells, BRG1 has been shown to not only modulate the expression of ATM and ATR but also to directly participate in DNA damage repair $(21,28,29)$.

Quantitative PCR analysis showed that the expression of RTT109, SNF2, TEL1, and MECl was downregulated in $\mathrm{FUN3mycHz}$ as well as $\mathrm{FUN3OHz}$ strains (Fig. 2A and B). The expression of these genes was restored when $F U N 30$ was overexpressed in $F U N 30 H z$ background ectopically under the regulation of $A C T 1$ promoter (Fig. 2B). Interestingly, the expression of the genes was also restored when RTT109 was overexpressed under the regulation of constitutive $A C T 1$ promoter in $\mathrm{FUN3OHz}$ background (Fig. 2B). 
To show Fun30 specifically regulates the expression of a subset of genes, the expression of three genes-RDN18 (encodes for 18S ribosomal RNA), EFB1 (encodes translation elongation factor beta), and $U B C 13$ (encodes for ubiquitin conjugating enzyme)was analysed. The expression of these genes was unchanged in $\mathrm{FUN3OmycHz}$ as compared to the FUN30myc wild type strain (Fig. 2C).

Western blots using anti-myc antibody confirmed that the expression of Fun30myc was reduced in the whole cell lysate of $F U N 30 m y c H z$ strain (Fig. 2D). However, the levels of H3ac (probed using anti-H3K56ac antibody) was not altered in the whole cell lysate of FUN3OmycHz (Fig. 2E). It needs to be pointed out that the antibody against H3K56ac is nonspecific and can also recognize $\mathrm{H} 3 \mathrm{~K} 9 \mathrm{ac}$ (30), and therefore, we can only conclude that though the transcript levels of RTT109 are downregulated, the total H3ac in the whole cell lysate is not altered.

\section{Fun30 binds to the promoter regions of the DNA damage response genes: To} assess whether Fun30 directly regulates the expression of RTT109, SNF2, TEL1 and MEC1 genes, ChIP assay was performed using anti-myc antibody to probe the interaction of Fun30myc protein with the promoter regions of these genes. In addition, the interaction of Fun30myc protein with the FUN30 promoter was also investigated to understand whether Fun30 regulates its own expression. Experimental results confirmed that Fun30 did bind to the promoter regions of these genes (Fig. 2F). In addition, the protein also bound to its own promoter indicating that it may be regulating itself (Fig. 2F). The occupancy of H3ac on the promoter regions of FUN30, RTT109, SNF2, TEL1, and MEC1 was found to be also reduced indicating that the global levels of $\mathrm{H} 3 \mathrm{ac}$ does not alter yet its recruitment to the promoter is affected in FUN3OmycHz mutant strain (Fig. 2G). The occupancy of Fun30 and H3ac on intergenic regions present in Chr5 as well as on GAPDH promoter was not altered indicating 
Fun30 specifically localizes to the promoter regions of the DNA damage response genes and regulates their expression (Fig. $2 \mathrm{H}$ and I).

H3ac regulates the expression of FUN30, SNF2, TEL1, and MEC1: As the above experiments showed that $\mathrm{H} 3 \mathrm{ac}$ is present on the promoter of DNA damage response genes and that overexpression of RTT109 restored the expression of the genes including FUN30, we asked whether a feedback loop exists in C. albicans wherein H3ac catalysed by Rtt109 regulates FUN30 in a manner similar to the feedback loop between SMARCAL1 and BRG1 in mammalian cells (23). The expression of FUN30 along with SNF2, TEL1 and MEC1 was analysed in cells where both copies of RTT109 was deleted to create homozygous null mutant, rtt109/rtt109 (hereafter termed as RTT109D), using PCR based strategies (Supplementary Fig. 4A and B). A revertant strain, rtt109/rtt109/pACT1-RTT109 (RTT109D/RTT109OE-URA3), was also created wherein RTT109 was cloned into pACT1 vector and integrated into RPS1 locus. As this strain in BWP17 was created using URA3 as the marker, all comparisons were done using BWP17-URA3 strain created specifically for this purpose. In FUN30myc, the two copies of RTT109 was deleted using HIS1 and ARG4 markers (Supplementary Fig. 4C).

Quantitative PCR showed that the expression FUN30, SNF2, TEL1, and MEC1 was downregulated in $R T T 109 D$ as compared to the wild type irrespective of the strain background (Fig. 3A and B). This downregulation was specific as RDN18, UBC13, and EFB1 expression was unaltered (Supplementary Fig. 4D). Overexpression of RTT109 under the control of ACT1 promoter in RTT109D background (RTT109D/RTT109OE-URA3) restored the expression level of these genes (Fig. 3A). Western blots confirmed that H3ac levels were downregulated in RTT109D mutant and restored back in RTT109D/RTT109OE$U R A 3$ strain (Fig. 3C). Interestingly, Fun30 expression was also not observed in RTT109D mutant (Fig. 3D). 
ChIP analysis showed that H3ac was present on the promoters of FUN30, SNF2, TEL1 and MEC1 (Fig. 3E). The occupancy of H3ac decreased in RTT109D mutant but was restored in RTT109OE strain (Fig. 3E). Finally, occupancy of Fun30myc tagged protein was also found to be decreased on the promoters of the DNA damage response genes in RTT109D mutant (Fig. 3F).

Thus, from these experimental results, it was concluded that both $\mathrm{H} 3 \mathrm{ac}$, catalysed by Rtt109, and Fun30 regulate the expression of each other as well as of SNF2, TEL1, and MEC1.

Overexpression of $F U N 30$ in $R T T 109 D$ mutant restores the gene expression: As the above studies indicated that the expression of FUN30 and RTT109 was co-regulated, therefore, we next asked whether overexpression of FUN30 in RTT109D can restore the gene expression and therefore, the defects observed in mutant strain. Therefore, FUN30 was overexpressed under the ACT1 promoter in RTT109D background (RTT109D/FUN30OEURA3). Quantitative PCR showed that the expression of SNF2, TEL1, and MEC1 was restored in this strain; however, the sensitivity to DNA damage agents was not restored (Fig. 3A and G). It has already been shown in S. cerevisiae that H3K56ac deposition on the newly replicated DNA strand is important for completion of DNA repair (31). Therefore, even though overexpression of Fun30 restores gene expression, DNA repair most probably continues to be impaired due to the absence of H3K56ac.

The catalytic activity of $\mathrm{Rtt109}$ is essential for the transcription regulation: The catalytic activity of Rtt109 requires the help of two chaperones- Asf1 and Vps75 (32). Therefore, we hypothesized that blocking the catalytic activity of Rtt109 by deleting VPS75 would also result in downregulation of RTT109, FUN30, SNF2, TEL1, and MEC1 expression. To test the hypothesis, one copy of Vps75 was deleted (VPS75/vps 75 referred hereinafter as $V P S 75 H z$ ) using PCR based strategy in BWP17 strain. Quantitative PCR confirmed that the 
expression of RTT109, FUN30, SNF2, TEL1, and MEC1 was indeed downregulated (Fig. 3H) in the mutant strain confirming that the catalytic activity of Rtt109 was essential for the transcriptional regulation mediated by $\mathrm{H} 3 \mathrm{ac}$.

\section{RTT109Hz/FUN30Hz double mutant shows differential response to genotoxic}

stress: To understand how Rtt109 and Fun30 regulate the DNA damage response pathway in the presence of genotoxic stress, double heterozygous mutant wherein one copy each of RTT109 and FUN30 (RTT109/rtt109;FUN30/fun30, hereinafter termed as RTT109Hz/FUN30Hz) was deleted BWP17. A similar mutant was made in FUN30myc strain and termed as RTT109Hz/FUN30mycHz. Quantitative PCR confirmed that the expression of RTT109, FUN30, SNF2, TEL1, and MEC1 was downregulated in both RTT109Hz/FUN30mycHz and RTT109/FUN30Hz strains (Fig. 4A and B). In contrast, the expression of $R D N 18, U B C 13$, and $E F B 1$ was unaltered (Fig. 4C). The ability of the RTT109Hz, FUN3OHz, RTT109Hz/FUN30mycHz and RTT109Hz/FUN3OHz to grow in the presence of $\mathrm{H}_{2} \mathrm{O}_{2}$ (generates ROS and induces base modifications), CPT (results in doublestrand breaks) and MMS (induces methylation of bases) was studied using plate (spot) assays. As compared to the wild type strain, both $\mathrm{RTT109Hz/FUN30mycHz}$ and RTT109Hz/FUN3OHz mutant showed no response to CPT (Fig. 4D and E), were sensitive to $\mathrm{H}_{2} \mathrm{O}_{2}$ (Fig. 4D and E) and resistant to MMS (Fig. 4D and E).

Thus, the response of the mutant strain appears to be dependent on the type of damage induced by the genotoxic agent.

\section{Rtt109 and Fun30 co-regulate the transcription of genes involved in DNA damage}

response pathways: Hydrogen peroxide, CPT and MMS activate base excision repair, double-strand repair, and mismatch repair pathway respectively (33-35). The Mec1 kinase is a central transducer in these pathways wherein after activation by phosphorylation it phosphorylates Rad9 and Mrc1. Rad9 functions in the DNA damage checkpoint (DDC) 
while Mrc1 is important for the DNA replication checkpoint (DRC) (36). Both proteins promote phosphorylation of Rad53, also known as effector kinase, by Mec1, thus, activating the cell cycle checkpoint. In addition, Rad5, an ATP-dependent chromatin remodelling protein as well as E3 ubiquitin ligase, is required for the bypass of replication forks through MMS-damaged DNA (37). In S. cerevisiae, Fun30 and Rad5 cooperate to repair the stalled replication fork. In the absence of Rad5, Fun30 null mutants show resistance to MMS (38).

We hypothesized that the DNA damage response is epigenetically regulated by H3ac (catalysed by Rtt109) and Fun30. Further, based on the plate assays, we postulated that in the presence of $\mathrm{H}_{2} \mathrm{O}_{2}, M E C 1, R A D 9$, and $M R C l$ would be downregulated in RTT109Hz/FUN3OHz strain as compared to the wild type strain; in the presence of CPT, the expression of $M E C 1, R A D 9$, and $M R C 1$ would be unchanged between the wild type and the mutant strain; and in the presence of MMS, the expression of RAD5 would be downregulated leading to resistance phenotype.

Therefore, the expression of $M E C 1, R A D 9, M R C 1$, and $R A D 5$ along with $F U N 30$, RTT109, SNF2, and TEL1 was evaluated in the mutant strain (RTT109/FUN30mycHz as well as RTT109/FUN30Hz) and compared with the wild type strain (FUN30myc and BWP17 respectively) in the absence and presence of the genotoxic stress.

Quantitative PCR showed that in the presence of $\mathrm{H}_{2} \mathrm{O}_{2}$, the expression of $F U N 30$, RTT109, SNF2, TEL1, MEC1, RAD9, MRC1, and RAD5 was downregulated in the mutant strain as compared to the wild type strain, thus, resulting in sensitive phenotype (Fig. 5 and Supplementary Fig. 5).

In contrast, in the presence of CPT, $M E C 1$ and $R A D 9$ expression was unchanged in the mutant strain as compared to the wild type strain (Fig. 5 and Supplementary Fig. 5). Interestingly, some strain specific differences were observed. The expression of FUN30, RTT109, SNF2, TEL1, RAD5 and MRC1 was unchanged in RTT109/FUN3OmycHz (Fig. 5). 
However, the expression of FUN30, RTT109, and SNF2 was downregulated while TEL1 was upregulated in RTT109Hz/FUN3OHz (Supplementary Fig. 5D). Taken together, in both strains, as $M E C 1$ expression is unchanged, we postulate that the DNA damage response is operational in the mutant strain in the presence of CPT, and therefore, no phenotypic response was observed to this stress agent.

In the presence of MMS too, expression of $M E C l$ was unchanged but the expression of TEL1, MRC1, and RAD5 was downregulated but $R A D 9$ was upregulated in the mutant strain as compared to the wild type strain (Fig. 5 and Supplementary Fig. 5).

Thus, our data shows that Rtt109 and Fun30 are epigenetically regulating the DNA damage response pathway depending on the type of DNA damage induced by the genotoxic stress.

The response to DNA damage is regulated by the occupancy of Fun30 on RAD9, MRC1, and RAD5 promoter: To understand how Rtt109 and Fun30 epigenetically regulate the DNA damage response pathway, ChIP experiments were performed to study the occupancy of H3ac and Fun30 on the promoters of FUN30, RTT109, SNF2, TEL1, MEC1, RAD9, MRC1, and RAD5 genes in FUN30myc and RTT109Hz/FUN3OmycHz mutant strain. In untreated cells, the occupancy of both Fun30myc and H3ac decreased on these gene promoters in the RTT109Hz/FUN3mycHz strain as compared to the FUN3Omyc wild type strain (Fig. 6A and B). The decreased occupancy correlates with decreases expression of these genes in the mutant strain as compared to the wild type strain.

When cells were treated with $\mathrm{H}_{2} \mathrm{O}_{2}$, the occupancy of Fun30 decreased on FUN30, RTT109, MEC1, MRC1, and RAD5 promoters in the mutant strain as compared to the wild type strain (Fig. 6C). The H3ac occupancy did not alter between the mutant and wild type strain on these promoters (Fig. 6D) indicating that Fun30 is the primary driver for the 
alteration of gene expression observed during oxidative stress. Thus, FUN30 but not RTT109 plays an important role in the response the cell mounts to oxidative stress.

On treatment with CPT, as expected, the occupancy of Fun30 and H3ac was similar in the wild type and mutant strain leading to no change in the gene expression between the two strains in the presence of this genotoxic agent (Fig. 6E and F).

Finally, when cells were treated with MMS, the occupancy of Fun30 and H3ac increased on $R A D 9$ promoter in the mutant strain as compared to the wild type strain (Fig. 6G and $\mathrm{H}$ ). Concomitantly, the occupancy of both Fun30 and H3ac decreased on MRC1 and $R A D 5$ promoters in the mutant strain as compared to the wild type strain (Fig. 6G and $\mathrm{H}$ ) leading to increased expression of $R A D 9$ and decreased expression of $M R C 1$ and $R A D 5$. Thus, on treatment with alkylating agent both Fun30 and H3ac epigenetically modulate the expression of the DNA damage response genes.

\section{Single copy deletion of RAD9 in $R T T 109 \mathrm{~Hz} / \mathrm{FUN} 30 \mathrm{~Hz}$, rescues the resistance to}

MMS: In presence of MMS, RAD9 is upregulated while RAD5 and MRC1 are downregulated in $\mathrm{RTT109Hz} / \mathrm{FUN3OHz}$ as well as $\mathrm{RTT109Hz} / \mathrm{FUN3OmycHz}$ as compared to the wild type strains.

In $S$. cerevisiae, deletion of both Rad5 and Fun30 results in resistance to MMS that can be rescued by overexpression of $R A D 5$ (38). To understand whether this pathway is operational in C. albicans also, RAD5 was ectopically overexpressed in $R T T 109 H z / F U N 30 H z$ mutant to generate $R T T 109 H z / F U N 30 H z / R A D 5 O E-U R A 3$ strain. As $U R A 3$ was used as a selection marker for making $R T T 109 H z / F U N 30 H z / R A D 5 O E-U R A 3$ strain and overexpression of this gene is known to affect growth, therefore, URA3 gene was incorporated in both BWP17 and RTT109Hz/FUN30Hz strain, creating BWP17-URA3 and RTT109Hz/FUN3OHz$U R A 3$ strains. In addition, RAD5 was also overexpressed in BWP17 (RAD5OE-URA3) to 
determine the effect of overexpression of this gene on growth and drug sensitivity in normal cells.

Quantitative PCR indicated that $R A D 5$ transcript was overexpressed in RTT109Hz/FUN30Hz/RAD5OE-URA3 strain as well as in RAD5OE-URA3 (Fig. 7A and Supplementary Fig. 6A). Plate assays showed that RTT109Hz/FUN3OHz/RAD5OE-URA3 mutant was slow growing as compared to BWP17-URA3 as well as RTT109Hz/FUN3OHz$U R A 3$ strains in YEPD plate in the absence of MMS (Fig. 7B). However, RAD5OE-URA3 did not show any growth difference as compared to BWP17-URA 3 (Supplementary Fig. 6B). In the presence of MMS, the growth of the RTT109Hz/FUN3OHz/RAD5OE-URA3 was slow as compared to RTT109Hz/FUN30Hz-URA3 mutant but it was impossible to determine whether this slow growth was because of rescue of the phenotype or was it because of the inherent slow growth of the mutant strain (Fig. 7B). It needs to be noted that RAD5OE-URA3 showed greater sensitivity to MMS as compared to BWP17-URA3 (Supplementary Fig. 6B). Therefore, to understand the effect of RAD5OE in RTT109Hz/FUN3OHz background, duplication time was calculated for the wild type and the mutant strain in the absence and presence of MMS. In the absence of MMS, RTT109Hz/FUN3OHz/RAD5OE-URA3 showed 4-fold slower growth as compared to the wild type strain (Fig. 7C and D). However, in the presence of MMS, the growth of RTT109Hz/FUN3OHz/RAD5OE-URA3 was slower as compared to RTT109Hz/FUN30Hz-URA3 mutant but faster than BWP17-URA3 suggesting $R A D 5$ overexpression can partially rescue the resistant phenotype of $R T T 109 H z / F U N 30 H z$ to MMS (Fig. 7C and D). However, comparison of the growth curve shows that the RTT109Hz/FUN30Hz/RAD5OE-URA3was not like that of the BWP17-URA3 (Fig. 7D).

Next, the role of $R A D 9$ was investigated. One copy of $R A D 9$ was deleted creating RTT109Hz/FUN3OHz/RAD9Hz-URA3. A control strain $R A D 9 H z-U R A 3$ was also created in BWP17 background be deleting one copy of the gene. Quantitative PCR confirmed the 


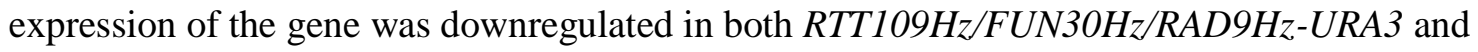
$R A D 9 H z-U R A 3$ strains (Fig. 7A and Supplementary Fig. 6C). Plate assays showed that RTT109Hz/FUN30Hz/RAD9Hz-URA3 and RAD9Hz-URA3 showed growth similar to BWP17-URA3 strain on YEPD plate (Fig. 7B and D; Supplementary Fig. 6B). Finally, in the presence of MMS, RTT109Hz/FUN3OHz/RAD9Hz-URA3 showed sensitivity like the BWP17-URA3 strain (Fig. 7B). It should be noted that $R A D 9 H z-U R A 3$ also shows greater sensitivity as compared to BWP17-URA3 (Supplementary Fig. 6B). Growth curves confirmed that the duplication time as well as the growth curve of RTT109Hz/FUN30Hz/RAD9Hz-URA3 and BWP17-URA3 are similar indicating that RAD9 overexpression is main reason for the resistance of $\mathrm{RTT109Hz} / \mathrm{FUN} 30 \mathrm{~Hz}$ in the presence of MMS (Fig. 7C and D). 


\section{DISCUSSION}

DNA damage induced by genotoxic stress activate the DNA damage response pathway. The pathway senses the DNA damage and transduces the message to the DNA damage repair proteins as well as cell checkpoint proteins to initiate DNA damage repair and cell cycle arrest. The Tel1 and Mec1 kinases belonging to the PIKK family are the central transducers of the DNA damage (27). These kinases are activated by autophosphorylation and in turn, phosphorylate the effector proteins. Amongst these are the mediator proteins, Rad9 and Mrc1, that on activation by phosphorylation transduces the signal to $\operatorname{Rad} 53$ (36, 39, 40). Rad53, in turn, induces cell cycle arrest $(41,42)$. In addition to Rad9 and Mrc1, Rad5, an ATP-dependent chromatin remodelling possessing E3 ubiquitination activity, is involved in the replication bypass mechanism when the bases are modified by alkylating agents (37). Studies have also shown that in addition to the role in activation of cell cycle checkpoint activation, Rad9 is required for transcription regulation of DNA damage response proteins (43) .

Though extensive studies have shown that the DNA damage response and the DNA damage repair pathways are regulated by post-transcriptional modification, very less information is available about the transcriptional regulation of these pathways.

In this paper, we show that Fun30, an ATP-dependent chromatin remodelling protein, and histone acetylation catalysed by Rtt109, a B-type histone acetyltransferase, transcriptionally co-regulate the response $C$. albicans mounts in the presence of genotoxic stress.

In $C$. albicans, unlike $S$. cerevisiae $(8,44)$, both copies of $F U N 30$ could not be deleted. However, in RTT109 null mutant, Fun30 expression could not be detected by western blot. Therefore, we do not know whether FUN30 is essential or whether our attempts to delete both copies were unsuccessful. 
Like $S$. cerevisiae Fun30, the $C$. albicans protein too possesses DNA-stimulated ATPase activity; however, whether the protein forms homodimer still needs to be determined (10). Using synthetic oligonucleotides, we found that the protein prefers fork DNA as effector unlike ADAAD which prefers stem-loop DNA (45) and Rad54 whose activity is stimulated by double-stranded DNA (46). Binding studies showed that the protein binds to ATP both in the absence and presence of fork DNA; however, the affinity for ATP decreases in the presence of fork DNA. The protein also binds to fork DNA both in the absence and presence of ATP. Further, like in the case of Rad54 (47), the affinity for the DNA does not change in the presence of ATP.

Quantitative PCR and ChIP studies showed that the Fun30 protein in C. albicans regulates the expression of $R T T 109, T E L 1, M E C 1, S N F 2, R A D 9, M R C 1$ and $R A D 5$. It is also present on its own promoter, possibly regulating itself.

RTT109 is non-essential and the protein encoded by this gene catalyses the formation of acetylated histones $(13,14)$. ChIP studies showed that H3ac is present on the promoters of FUN30, RTT109, TEL1, MEC1, SNF2, RAD9, MRC1 and RAD5; the occupancy of H3ac decreases on these promoters when both copies of RTT109 are deleted correlating with decreased expression.

Thus, FUN30 and RTT109 both regulate the expression of each other as well as of other DNA damage response genes. ChIP and qPCR data, interestingly, reveal that both Fun30 and H3ac can drive the expression of the DNA damage response genes in the absence of RTT109 and FUN30 respectively. However, both Fun30 and H3ac are necessary for mediating the response to genotoxic stress as overexpression of FUN30 in RTT109D strain does not overcome the sensitivity shown by the mutant strain to genotoxic stress.

The double heterozygous mutant RTT109Hz/FUN3OHz helped to elucidate how these two genes regulate the expression of the DNA damage response genes in the presence of 
different genotoxic agents. $R T T 109 \mathrm{~Hz} / F U N 30 \mathrm{~Hz}$ shows sensitivity to $\mathrm{H}_{2} \mathrm{O}_{2}$, no response to CPT, and resistance to MMS as compared to the wild type cells. qPCR data showed that in the presence of CPT, which induces double-strand break, the expression of the DNA damage response genes are upregulated in $\mathrm{RTT109Hz} / \mathrm{FUN} 30 \mathrm{~Hz}$ indicating that the remaining one copy of the two genes is sufficient for the process.

The $R T T 109 H z / F U N 30 H z$ mutant is unable to cope with the induction of oxidative stress as the expression of $M E C 1, R A D 9, M R C 1$ and $R A D 5$ are downregulated. This downregulation is primarily mediated by the absence of Fun30 as the occupancy of H3ac in the mutant is similar to the wild type. The recruitment of Fun30 to the promoter of the DNA damage response genes in the event of oxidative stress, on the other hand, is impaired leading to downregulation of the genes involved in the DNA damage response pathway resulting in the inactivation of the response/repair. Thus, RTT109 and FUN30 are essential for the survival of C. albicans in the presence of ROS/oxidative stress.

When cells are treated with MMS, the DNA bases (G and A, primarily) are methylated. In the mutant cells, on treatment with MMS, the occupancy of Fun30 and H3ac on the promoter of $R A D 5$ decreases leading to reduced expression of Rad5 protein. On the other hand, the occupancy of Fun30 and $\mathrm{H} 3 \mathrm{ac}$ increased on $R A D 9$ promoter correlating with increased expression of this gene.

Methylation of bases results in the stalling of the replication fork and Rad5 plays an important role in the bypass of the stalled replication fork either by recruiting DNA pol $\eta$ (TLS pathway) or by polyubiquitinating PCNA and bypassing the replication fork (48). By mechanism possibly involving Rad51 and HR mediated repair, deletion of both Fun30 and Rad5 in S. cerevisiae has been shown to result in resistance to MMS (38). In RTT109Hz/FUN30Hz mutant cells, the expression of RAD5 and MRC1 is downregulated but not completely abolished. It is possible that reduced expression of $R A D 5$ results in the 
bypass TLS pathway leading to faster DNA replication and thus, more growth. However, FACS studies will need to be done to confirm this hypothesis. It also needs to be noted that overexpression of RAD5 only partially restores sensitivity to MMS indicating that the reduced expression of this gene might not be the primary driver for resistance to MMS in the RTT109Hz/FUN3OHz strain.

Concomitantly, the expression of $R A D 9$ is upregulated in $R T T 109 H z / F U N 3 O H z$ cells on treatment with MMS. Deletion of one copy of RAD9 in $R T T 109 H z / F U N 30 H z$ led to restoration of sensitive phenotype in the presence of MMS. Rad9 is known to inhibit DNA end-resection and studies in S. cerevisiae has shown that Fun30 inhibits Rad9 to promote DNA end-resection during DNA double-strand break repair (49). Both Fun30 and Rad9 are known to play a role in resistance to MMS; however, the crosstalk between RTT1109, FUN30 and $R A D 9$ in $C$. albicans in determining the response to MMS needs to be further studied.

Thus, our studies show that the DNA damage response as well as the repair pathway are epigenetically modulated in C. albicans. 


\section{MATERIALS AND METHODS}

Chemicals: All chemicals used in this study were of analytical grade and were purchased either from Thermo Fisher Scientific (USA), or Merck (India), or HiMedia (India), or SRL (India), or Sigma-Aldrich (USA). The media for growing cells were purchased from HiMedia (India). Restriction enzymes and T4 DNA ligase were purchased from Thermo Fisher Scientific (USA), Merck (USA) and New England Biolabs (USA). TA cloning kit was purchased from MBI Fermentas (USA). Gel extraction kit was purchased from Qiagen (Germany). SYBR Green was purchased from Kapa Biosystems (Switzerland). Bradford dye for protein estimation was purchased from Sigma-Aldrich (USA). All the primers were synthesized by GCC Biotech (India) (Table S1).

Plasmids and strains: E.coli strain JM109 (Merck, India) was used for cloning RTT109, FUN30 and RAD5. Two C. albicans strains BWP17 and SN152 were used in this study and all mutants were made in these backgrounds. BWP17 was a kind gift from Prof. Aaron P. Mitchell, Department of Biological Sciences, Carnegie Mellon University, Pittsburgh, PA, USA. SN152 strain was a kind gift from Prof. Natarajan, JNU and BWP17$U R A 3$ strain was a kind gift from Prof. S.S.Komath, JNU. The plasmids and strains used in this study are listed in Table S2 and Table S3 respectively.

C. albicans strains were cultured in Yeast Extract-Peptone-Dextrose (YEPD) media or in synthetic dextrose (SD) minimal media. Ura ${ }^{-}$strains were cultured in SD media supplemented with $60 \mu \mathrm{g} / \mathrm{ml}$ uridine. His ${ }^{-}$strains or $\mathrm{Arg}^{-}$strains were cultured in SD medium supplemented with $85.6 \mu \mathrm{g} / \mathrm{ml}$ histidine or arginine. Transformations were performed using Lithium acetate method (50).

Antibodies: Antibodies of anti-H3 (Cat\# 96C10) was purchased from Cell Signalling Technologies (USA), anti-H3K56ac (Cat\# 76307) was purchased from Abcam (UK), anti-c- 
Myc (Cat\# ITG0001) was purchased from Immunotag (USA) and anti-G6PDH (Cat\# A9521) was purchased from Sigma-Aldrich (USA).

Generation of heterozygous and deletion mutants: PCR-mediated gene disruption strategy was used for making all the mutants in C. albicans. Heterozygous mutants of RTT109, FUN30 and VPS75 of were made using the selection marker HIS1. Heterozygous mutant of $R A D 9$ was made using the selection marker URA3. For making RTT109 deletion mutant, the second copy of RTT109 was replaced with ARG4 selection marker and transformed in $R T T 109 \mathrm{~Hz}$ background. For $R T T 109 \mathrm{~Hz} / \mathrm{FUN} 30 \mathrm{~Hz}$ mutant, one copy of RTT109 was replaced with HIS1 followed by replacing one copy of FUN30 with ARG4 selection marker. $R T T 109 \mathrm{~Hz} / F U N 30 / \mathrm{Hz} / \mathrm{RAD} 9 \mathrm{~Hz}-U R A 3$ was created by replacing $R A D 9$ with $U R A 3$ selection marker in $R T T 109 H z / F U N 30 H z$ background. The HIS1, ARG4 and URA3 were amplified by PCR using primers that included flanking gene specific sequence and transformed in the respective $C$. albicans strain. Selection of transformants was done in SD media plate without Histidine or Arginine or Uridine and confirmed by PCR using gene specific flanking primers.

Generation of overexpression strains: One allele of RTT109 and FUN30 were introduced into the FUN3OHz and RTT109D backgrounds respectively. One allele of RAD5 was introduced into $R T T 109 \mathrm{~Hz} / F U N 30 H z$ as well as BWP17 strain. For creating the overexpression strains, RTT109, FUN30 and RAD5 were cloned under ACT1 promoter in pACT1-GFP vector. RTT109 was cloned between the HindIII and NheI sites while FUN30 was cloned between PstI and Nhe1 sites. RAD5 was cloned into pACT1-GFP vector between the HindIII and NheI sites. The constructs generated were linearized using StuI restriction enzyme and introduced into the respective backgrounds. The transformants were selected on media plate without uridine. The successful transformants were screened by PCR, using gene specific forward primer (FP; Table S1) and locus specific RPS1 reverse primer (RP; Table 
S1) to confirm the integration at RPS1 locus. URA3 expressing control strains were made by digesting $\mathrm{pACT1-GFP}$ vector, which has URA3 promoter, with Stu1 and transformed.

Generation of revertant strains: Revertant strains of RTT109 and FUN30 in RTT109 deleted and FUN30 heterozygous background respectively were performed similarly, as described above.

Epitope-tagging of endogenous FUN30: pADH34 vector, a kind gift of Prof. Johnson, UCSF, was used to add 13X-Myc tag to C-terminus of endogenous FUN30 of $C$. albicans. Briefly, fusion PCR method was used to generate appropriate double-stranded DNA which was transformed into SN152 strain. The DNA was integrated into the site by homologous recombination and transformed colonies were selected using nourseothricin selection media plate. This strain was termed as FUN30myc and all the mutants were made in this background. This strain was used as the control wild type for ChIP, qPCR and plate assays.

Quantitative PCR (qPCR): Cells was taken from late log phase secondary culture to isolate the RNA. The cells were collected by centrifugation and then washed twice with DEPC-treated water. The cells were lysed by vortexing with glass beads. TRIzol reagent (Qiagen) was added to the cell pellet to extract the total RNA. cDNA was prepared using 2 $\mu \mathrm{g}$ of total RNA. The transcript levels of different genes were quantified by amplifying with qPCR primers (Table S4) using SYBR Green PCR master mix. GAPDH transcripts levels were used as internal control for all the experiments.

Chromatin Immunoprecipitation (ChIP) assay: Briefly, cells from late log phase secondary culture was harvested after fixing with formaldehyde ( $1 \%$ final concentration) for $20 \mathrm{~min}$. Then glycine $(25 \mathrm{mM})$ was added to quench the formaldehyde and the cells were incubated for $10 \mathrm{~min}$. Following this step, the cells were treated with $5 \mathrm{U}$ lyticase enzyme for $2 \mathrm{hr}$. Subsequently, the cells were pelleted down, washed and lysed in lysis buffer (50 mM 
HEPES, pH 7.5; 140 mM NaCl; 1 mM EDTA; $1 \%$ Triton X-100; 1 mM PMSF) with glass beads and vortexed. The supernatant was sonicated using a water bath sonicator (five cycles of $15 \mathrm{sec}$ ON and $15 \mathrm{sec}$ OFF each). After sonication, chromatin of different mutants was incubated overnight with respective antibodies. Then, protein $\mathrm{G}$ agarose beads were added for binding with the antibody. The beads were subsequently washed with lysis buffer, high-salt buffer (lysis buffer with $500 \mathrm{mM} \mathrm{NaCl}$ ), wash buffer (10 mM Tris-Cl, pH 8.0; $250 \mathrm{mM} \mathrm{LiCl}$; 1 mM EDTA; $0.5 \%$ NP-40) and Tris-EDTA buffer. Finally, elution buffer (1.0\% SDS; 100 $\mathrm{mM} \mathrm{NaHCO}$ ) was added to elute the protein-DNA complex and the protein was digested using proteinase K. The DNA was extracted using phenol: chloroform mixture (1:1) and then precipitated with iso-propanol. The ChIP samples were analyzed by qPCR using promoter region specific primers (Table S5).

Western blots: Cells were taken from $8 \mathrm{hr}$ secondary culture at $30^{\circ} \mathrm{C}$ and lysates were prepared in ice-cold lysis buffer (50 mM Tris-Cl, pH 7.5; $150 \mathrm{mM} \mathrm{NaCl} ; 50 \mathrm{mM} \mathrm{NaF}$; $1 \%$ Triton X-100; 0.1\% SDS; 3 mM PMSF) using glass beads. The lysate was centrifuged at $16000 \mathrm{RCF}$ and supernatant were taken to measure the protein concentration. The protein samples were separated by SDS-PAGE. Protein was then transferred from gel to a PVDF membrane. Membrane blocking was performed with 5\% skimmed milk in PBS for $1 \mathrm{hr}$. The blot was then probed with respective primary antibody at $4{ }^{\circ} \mathrm{C}$ for overnight followed by washing three times with PBST (PBS $+0.05 \%$ Tween 20). The blots were incubated with appropriate secondary antibodies. Subsequently, the blots were washed thrice with PBST (10 min per wash) and developed using chemiluminescence.

Immunofluorescence: Cells from secondary culture were fixed with $37 \%$ formaldehyde. After washing the cell pellet with $1 \mathrm{X}$ PBS, 5U lyticase treatment was given to digest the cell wall. Triton X-100 was used to permeabilize the cells. Cells were resuspended in blocking solution (1\% BSA in $1 \mathrm{X}$ PBS). Primary c-Myc antibody was added in a dilution 
of 1: 100 to the cells and then incubated overnight at $4{ }^{\circ} \mathrm{C}$. The cells were pelleted, washed with PBS, and resuspended in appropriate secondary antibody solution. Hoechst dye was added to it and incubation was continued for $30 \mathrm{~min}$. The cells were pelleted, washed with PBS and mounted on glass slides. The slides were analysed Nikon A1R confocal microscope.

Growth rate analysis: A primary culture was grown in $10 \mathrm{ml} \mathrm{YEPD} \mathrm{media} \mathrm{at} 30^{\circ} \mathrm{C}$. 0.1 OD cells from the primary culture was added in secondary culture media and incubated at $30^{\circ} \mathrm{C}, 220 \mathrm{rpm}$. $\mathrm{OD}$ at $\mathrm{A}_{600 \mathrm{~nm}}$ was monitored with the aliquots taken from secondary culture every $2 \mathrm{hr}$ until saturation was reached. The growth curve was obtained from the OD values and doubling time was calculated.

Plate assays: Cells from secondary culture of different mutants were measured at 0.1 OD at $\mathrm{A}_{600 \mathrm{~nm}}$ and diluted accordingly with $0.9 \%$ saline. A total of five samples of fivefold serial dilution were prepared and spotted on control plates as well as different treated plates. Images were taken for interpretation of results. All plate assays were repeated at least 3 times and the best representative image is shown in the manuscript.

Overexpression and purification of Fun30: FUN30 from C. albicans was cloned in pET-21c (+) vector between NheI and XhoI. Plasmid DNA was isolated from the transformant and transformed into Rosetta (DE3) cells (Merck Millipore, USA). For purification, a single colony of the transformed cell was inoculated into $10 \mathrm{ml}$ of LB containing $100 \mu \mathrm{g} / \mathrm{ml}$ ampicillin and $50 \mathrm{mg} / \mathrm{ml}$ chloramphenicol. The cells were grown for 16 $\mathrm{hr}$ at $37^{\circ} \mathrm{C}$ and $1 \%(\mathrm{v} / \mathrm{v})$ of the primary inoculum was transferred to fresh LB medium containing ampicillin and chloramphenicol. The cells were grown to an optical density of 0.6 , induced with $0.5 \mathrm{mM}$ IPTG and grown at $16^{\circ} \mathrm{C}$ for $16 \mathrm{hr}$. The cells were harvested by centrifugation at $5000 \mathrm{rpm}$ for $10 \mathrm{~min}$ at $4{ }^{\circ} \mathrm{C}$ and resuspended in lysis buffer containing 25 $\mathrm{mM}$ Tris-Cl pH 7.5, $350 \mathrm{mM} \mathrm{NaCl}, 5 \mathrm{mM} \beta$-mercaptoethanol, $0.5 \mathrm{mM}$ PMSF, and $0.1 \mathrm{mg} / \mathrm{ml}$ lysozyme. The cells were homogenized and incubated for $1 \mathrm{hr}$ at $4{ }^{\circ} \mathrm{C}$. The cells were lysed 
by sonication for 5 cycles ( 15 seconds $\mathrm{ON}$ and 45 seconds OFF). After the sonication, cell debris was removed by centrifugation at $12000 \mathrm{rpm}$ for $45 \mathrm{~min}$ at $4{ }^{\circ} \mathrm{C}$, and the supernatant was loaded onto $\mathrm{Ni}^{2+}$-NTA (GE Healthcare, USA) column pre-equilibrated in equilibration buffer containing $25 \mathrm{mM}$ Tris- $\mathrm{Cl} \mathrm{pH}$ 7.5, $350 \mathrm{mM} \mathrm{NaCl}, 5 \mathrm{mM} \beta$-mercaptoethanol, and 0.5 mM PMSF. The column was washed, and the bound protein was eluted with buffer containing $200 \mathrm{mM}$ imidazole, $25 \mathrm{mM}$ Tris-Cl pH 7.5, $350 \mathrm{mM} \mathrm{NaCl}, 5 \mathrm{mM} \beta$ mercaptoethanol, and $0.5 \mathrm{mM}$ PMSF. The fractions containing the protein were pooled and imidazole was removed by dialyzing the protein against buffer containing $25 \mathrm{mM}$ Tris- $\mathrm{Cl} \mathrm{pH}$ 7.5, $100 \mathrm{mM} \mathrm{NaCl}, 15 \%$ (v/v) glycerol, and $5 \mathrm{mM} \beta$-mercaptoethanol. Further purification, if necessary, was done using DE52 column. The concentration of the purified protein was determined using Bradford reagent.

ATPase activity: The ATPase activity of the Fun30 was estimated using NADH coupled oxidation assay. For this assay, $0.2 \mu \mathrm{M}$ of protein was added in $1 \mathrm{X}$ REG buffer containing $25 \mathrm{mM}$ Tris-OAc pH 7.5, 6 mM MgOAc, $60 \mathrm{mM}$ KOAc, $5 \mathrm{mM} \beta$ mercaptoethanol, $1.4 \mathrm{mg} / \mathrm{ml}$ phosphoenol pyruvate (PEP) and 10 units each of pyruvate kinase $(\mathrm{PK})$ and lactate dehydrogenase $(\mathrm{LDH})$ in a $250 \mu \mathrm{l}$ reaction volume. ATP and NADH were added to final concentrations of $2 \mathrm{mM}$ and $0.1 \mathrm{mg} / \mathrm{ml}$, respectively. The reaction mixture was incubated for $60 \mathrm{~min}$ at $30^{\circ} \mathrm{C}$. The change in absorbance was recorded at $340 \mathrm{~nm}$ and the concentration of NADH oxidized was calculated using molar extinction coefficient of NADH as $6.3 \mathrm{mM}^{-1}$. For DNA-stimulated ATPase activity, $500 \mathrm{nM}$ concentration of singlestranded DNA (ssDNA), double-stranded DNA (dsDNA), stem-loop DNA (sIDNA), fork DNA, and replication fork DNA were used. The sequence of these DNA molecules is provided in Table S6.

Fluorescence studies: Ligand binding study based on tryptophan specific excitation were conducted using fluorescence spectrophotometer (Cary Eclipse fluorimeter). The 
concentration of Fun30 used for fluorescence studies was $0.5 \mu \mathrm{M}$. All the experiments were done in room temperature in the buffer containing $50 \mathrm{mM}$ Tris-SO $4 \mathrm{pH} 7.5,5 \mathrm{mM} \beta$ mercaptoethanol and $1 \mathrm{mM} \mathrm{MgSO}$. The excitation wavelength was $295 \mathrm{~nm}$, and the emission wavelength was $340 \mathrm{~nm}$. The slit widths were 5 and $10 \mathrm{~nm}$, respectively. The spectra obtained were corrected for dilution and the inner filter effect was negligible. The binding data obtained were fit to a one-site saturation for the interaction of the ligand with the protein. The $K_{\mathrm{d}}$ was calculated using the equation

$\Delta F / F o=B_{\max }[\mathrm{L}] /\left(K_{d}+[\mathrm{L}]\right)$

Where $B_{\max }$ is the maximal binding, [L] is the ligand concentration, and $K_{\mathrm{d}}$ is the dissociation constant.

Phylogenetic, Domain, and motif analysis: Phylogenetic analysis of uncharacterised Fun30 protein sequence from C. albicans was done using www.phylogeny.fr/version2 cgi/ using default settings. The protein sequences of different ATP-dependent chromatin remodelling proteins from various organisms belonging to different families were extracted from NCBI. Multiple sequence alignment was performed using T-COFFEE Multiple sequence alignment (http://tcoffee.crg.cat/). The domain architecture of Fun30 and $\Delta$ NFun30 from C. albicans was created using https://prosite.expasy.org/mydomains/ website in its default settings. To identify the conserved motif sequences in Fun30 from C. albicans, motif analysis was done using http://tcoffee.crg.cat/apps/tcoffee/do:psicoffee website.

For phylogenetic and motif analysis, orf19.6291 protein from C. albicans, Rad5 from S. cerevisiae, Rad16 from S. cerevisiae, Lodestar from D. melanogaster, Etl1 from M. musculus and SMARCAD1 from H. sapiens, Fun30 from S. cerevisiae, Fft1, Fft2, and Fft3 from S. pombe, Iswi from D. melanogaster, Snf2 from S. cerevisiae, BRG1, BRM, and CHD7 from H. sapiens, Mi-2 from D. melanogaster, CHD1 from S. cerevisiae, EP400 from H. sapiens and M. musculus, SWR1 from S. cerevisiae and C. elegans, Ino80 from $H$. 
bioRxiv preprint doi: https://doi.org/10.1101/2021.07.22.453354; this version posted July 22, 2021. The copyright holder for this preprint (which

was not certified by peer review) is the author/funder, who has granted bioRxiv a license to display the preprint in perpetuity. It is made available under aCC-BY-NC-ND 4.0 International license.

sapiens, S. cerevisiae and C. elegans, ERCC6 from H. sapiens, ATRX from H. sapiens,

Rad54 from S. cerevisiae, SMARCAL1 from $H$. sapiens and Mot1 from $S$. cerevisiae were

used. 


\section{REFERENCES}

1. Morettini S, Podhraski V, Lusser A. 2008. ATP-dependent chromatin remodeling enzymes and their various roles in cell cycle control. Front Biosci J Virtual Libr $13: 5522-5532$.

2. Flaus A, Martin DMA, Barton GJ, Owen-Hughes T. 2006. Identification of multiple distinct Snf2 subfamilies with conserved structural motifs. Nucleic Acids Res 34:28872905.

3. Gorbalenya AE, Koonin EV. 1993. Helicases: amino acid sequence comparisons and structure-function relationships. Curr Opin Struct Biol 3:419-429.

4. Flaus A, Owen-Hughes T. 2011. Mechanisms for ATP-dependent chromatin remodelling: the means to the end. FEBS J 278:3579-3595.

5. Mizuguchi G, Shen X, Landry J, Wu W-H, Sen S, Wu C. 2004. ATP-driven exchange of histone $\mathrm{H} 2 \mathrm{AZ}$ variant catalyzed by SWR1 chromatin remodeling complex. Science 303:343-348.

6. Eapen VV, Sugawara N, Tsabar M, Wu W-H, Haber JE. 2012. The Saccharomyces cerevisiae Chromatin Remodeler Fun30 Regulates DNA End Resection and Checkpoint Deactivation. Mol Cell Biol 32:4727-4740.

7. Costelloe T, Louge R, Tomimatsu N, Mukherjee B, Martini E, Khadaroo B, Dubois K, Wiegant WW, Thierry A, Burma S, van Attikum H, Llorente B. 2012. The yeast Fun30 and human SMARCAD1 chromatin remodellers promote DNA end resection. Nature.

8. Neves-Costa A, Will WR, Vetter AT, Miller JR, Varga-Weisz P. 2009. The SNF2Family Member Fun30 Promotes Gene Silencing in Heterochromatic Loci. PLoS ONE $4: \mathrm{e} 8111$.

9. Steglich B, Strålfors A, Khorosjutina O, Persson J, Smialowska A, Javerzat J-P, Ekwall K. 2015. The Fun30 chromatin remodeler Fft3 controls nuclear organization and 
chromatin structure of insulators and subtelomeres in fission yeast. PLoS Genet 11:e1005101.

10. Awad S, Ryan D, Prochasson P, Owen-Hughes T, Hassan AH. 2010. The Snf2 homolog Fun30 acts as a homodimeric ATP-dependent chromatin-remodeling enzyme. J Biol Chem 285:9477-9484.

11. Schneider J, Bajwa P, Johnson FC, Bhaumik SR, Shilatifard A. 2006. Rtt109 Is Required for Proper H3K56 Acetylation A chromatin mark associated with the elongating RNA polymerase II. J Biol Chem 281:37270-37274.

12. D'Arcy S, Luger K. 2011. Understanding histone acetyltransferase Rtt109 structure and function: how many chaperones does it take? Curr Opin Struct Biol 21:728-734.

13. Driscoll R, Hudson A, Jackson SP. 2007. Yeast Rtt109 promotes genome stability by acetylating histone H3 on lysine 56. Science 315:649-652.

14. Rosa JL da, Boyartchuk VL, Zhu LJ, Kaufman PD. 2010. Histone acetyltransferase Rtt109 is required for Candida albicans pathogenesis. Proc Natl Acad Sci 107:15941599.

15. Vempati RK, Jayani RS, Notani D, Sengupta A, Galande S, Haldar D. 2010. p300mediated Acetylation of Histone H3 Lysine 56 Functions in DNA Damage Response in Mammals. J Biol Chem 285:28553-28564.

16. Tang Y, Holbert MA, Wurtele H, Meeth K, Rocha W, Gharib M, Jiang E, Thibault P, Verreault A, Cole PA, Marmorstein R. 2008. Fungal Rtt109 histone acetyltransferase is an unexpected structural homolog of metazoan p300/CBP. Nat Struct Mol Biol 15:738745.

17. Dantas A, Day A, Ikeh M, Kos I, Achan B, Quinn J. 2015. Oxidative Stress Responses in the Human Fungal Pathogen, Candida albicans. Biomolecules 5:142-165. 
18. Jain P, Garai P, Sethi SC, Naqvi N, Yadav B, Kumar P, Singh SL, Yadav U, Bhatnagar S, Rahul null, Puri N, Muthuswami R, Komath SS. 2019. Modulation of azole sensitivity and filamentation by GPI15, encoding a subunit of the first GPI biosynthetic enzyme, in Candida albicans. Sci Rep 9:8508.

19. Inglis DO, Arnaud MB, Binkley J, Shah P, Skrzypek MS, Wymore F, Binkley G, Miyasato SR, Simison M, Sherlock G. 2012. The Candida genome database incorporates multiple Candida species: multispecies search and analysis tools with curated gene and protein information for Candida albicans and Candida glabrata. Nucleic Acids Res 40:D667-D674.

20. Shih SC, Prag G, Francis SA, Sutanto MA, Hurley JH, Hicke L. 2003. A ubiquitinbinding motif required for intramolecular monoubiquitylation, the CUE domain. EMBO J 22:1273-1281.

21. Sethy R, Rakesh R, Patne K, Arya V, Sharma T, Haokip DT, Kumari R, Muthuswami R. 2018. Regulation of ATM and ATR by SMARCAL1 and BRG1. Biochim Biophys Acta Gene Regul Mech 1861:1076-1092.

22. Patne K, Rakesh R, Arya V, Chanana UB, Sethy R, Swer PB, Muthuswami R. 2017. BRG1 and SMARCAL1 transcriptionally co-regulate DROSHA, DGCR8 and DICER in response to doxorubicin-induced DNA damage. Biochim Biophys Acta 1860:936-951.

23. Haokip DT, Goel I, Arya V, Sharma T, Kumari R, Priya R, Singh M, Muthuswami R. 2016. Transcriptional Regulation of ATP-Dependent Chromatin Remodeling Factors: SMARCAL1 and BRG1 Mutually Co-Regulate Each Other. Sci Rep 6:20532.

24. Byeon B, Wang W, Barski A, Ranallo RT, Bao K, Schones DE, Zhao K, Wu C, Wu WH. 2013. The ATP-dependent chromatin remodeling enzyme Fun30 represses transcription by sliding promoter-proximal nucleosomes. J Biol Chem 288:2318223193. 
25. Lee J, Choi ES, Seo HD, Kang K, Gilmore JM, Florens L, Washburn MP, Choe J, Workman JL, Lee D. 2017. Chromatin remodeller Fun30Fft3 induces nucleosome disassembly to facilitate RNA polymerase II elongation. Nat Commun 8:14527.

26. Lee J, Choi ES, Lee D. 2018. It's fun to transcribe with Fun30: A model for nucleosome dynamics during RNA polymerase II-mediated elongation. Transcription 9:108-116.

27. Craven RJ, Greenwell PW, Dominska M, Petes TD. 2002. Regulation of genome stability by TEL1 and MEC1, yeast homologs of the mammalian ATM and ATR genes. Genetics 161:493-507.

28. Lee H-S, Park J-H, Kim S-J, Kwon S-J, Kwon J. 2010. A cooperative activation loop among SWI/SNF, $\gamma$-H2AX and H3 acetylation for DNA double-strand break repair. EMBO J 29:1434-1445.

29. Kwon S-J, Park J-H, Park E-J, Lee S-A, Lee H-S, Kang SW, Kwon J. 2015. ATMmediated phosphorylation of the chromatin remodeling enzyme BRG1 modulates DNA double-strand break repair. Oncogene 34:303-313.

30. Pal S, Graves H, Ohsawa R, Huang T, Wang P, Harmacek L, Tyler J. 2016. The Commercial Antibodies Widely Used to Measure H3 K56 Acetylation Are Non-Specific in Human and Drosophila Cells. PLOS ONE 11:e0155409.

31. Wurtele H, Kaiser GS, Bacal J, St-Hilaire E, Lee E-H, Tsao S, Dorn J, Maddox P, Lisby M, Pasero P, Verreault A. 2012. Histone H3 lysine 56 acetylation and the response to DNA replication fork damage. Mol Cell Biol 32:154-172.

32. Tsubota T, Berndsen CE, Erkmann JA, Smith CL, Yang L, Freitas MA, Denu JM, Kaufman PD. 2007. Histone H3-K56 acetylation is catalyzed by histone chaperonedependent complexes. Mol Cell 25:703-712.

33. Stojic L, Brun R, Jiricny J. 2004. Mismatch repair and DNA damage signalling. DNA Repair 3:1091-1101. 
34. Henle ES, Linn S. 1997. Formation, prevention, and repair of DNA damage by iron/hydrogen peroxide. J Biol Chem 272:19095-19098.

35. Pommier Y. 2006. Topoisomerase I inhibitors: camptothecins and beyond. Nat Rev Cancer 6:789-802.

36. Osborn AJ. 2003. Mrc1 is a replication fork component whose phosphorylation in response to DNA replication stress activates Rad53. Genes Dev 17:1755-1767.

37. Unk I, Hajdú I, Blastyák A, Haracska L. 2010. Role of yeast Rad5 and its human orthologs, HLTF and SHPRH in DNA damage tolerance. DNA Repair 9:257-267.

38. Bi X, Yu Q, Siler J, Li C, Khan A. 2015. Functions of Fun30 chromatin remodeler in regulating cellular resistance to genotoxic stress. PloS One 10:e0121341.

39. Alcasabas AA, Osborn AJ, Bachant J, Hu F, Werler PJ, Bousset K, Furuya K, Diffley JF, Carr AM, Elledge SJ. 2001. Mrc1 transduces signals of DNA replication stress to activate Rad53. Nat Cell Biol 3:958-965.

40. Schwartz MF, Duong JK, Sun Z, Morrow JS, Pradhan D, Stern DF. 2002. Rad9 phosphorylation sites couple Rad53 to the Saccharomyces cerevisiae DNA damage checkpoint. Mol Cell 9:1055-1065.

41. Allen JB, Zhou Z, Siede W, Friedberg EC, Elledge SJ. 1994. The SAD1/RAD53 protein kinase controls multiple checkpoints and DNA damage-induced transcription in yeast. Genes Dev 8:2401-2415.

42. Neecke H. 1999. Cell cycle progression in the presence of irreparable DNA damage is controlled by a Mec1- and Rad53-dependent checkpoint in budding yeast. EMBO J $18: 4485-4497$.

43. Aboussekhra A, Vialard JE, Morrison DE, de la Torre-Ruiz MA, Cernáková L, Fabre F, Lowndes NF. 1996. A novel role for the budding yeast RAD9 checkpoint gene in DNA damage-dependent transcription. EMBO J 15:3912-3922. 
44. Durand-Dubief M, Will WR, Petrini E, Theodorou D, Harris RR, Crawford MR,

Paszkiewicz K, Krueger F, Correra RM, Vetter AT, Miller JR, Kent NA, Varga-Weisz

P. 2012. SWI/SNF-Like Chromatin Remodeling Factor Fun30 Supports Point

Centromere Function in S. cerevisiae. PLoS Genet 8:e1002974.

45. Nongkhlaw M, Dutta P, Hockensmith JW, Komath SS, Muthuswami R. 2009.

Elucidating the mechanism of DNA-dependent ATP hydrolysis mediated by DNAdependent ATPase A, a member of the SWI2/SNF2 protein family. Nucleic Acids Res $37: 3332-3341$.

46. Swagemakers SM, Essers J, de Wit J, Hoeijmakers JH, Kanaar R. 1998. The human RAD54 recombinational DNA repair protein is a double-stranded DNA-dependent ATPase. J Biol Chem 273:28292-28297.

47. Dürr H, Körner C, Müller M, Hickmann V, Hopfner K-P. 2005. X-ray structures of the Sulfolobus solfataricus SWI2/SNF2 ATPase core and its complex with DNA. Cell 121:363-373.

48. Ortiz-Bazán MÁ, Gallo-Fernández M, Saugar I, Jiménez-Martín A, Vázquez MV, Tercero JA. 2014. Rad5 plays a major role in the cellular response to DNA damage during chromosome replication. Cell Rep 9:460-468.

49. Chen X, Cui D, Papusha A, Zhang X, Chu C-D, Tang J, Chen K, Pan X, Ira G. 2012. The Fun30 nucleosome remodeller promotes resection of DNA double-strand break ends. Nature 489:576-580.

50. Walther A, Wendland J. 2003. An improved transformation protocol for the human fungal pathogen Candida albicans. Curr Genet 42:339-343. 


\section{AUTHOR CONTRIBUTIONS}

Conceptualization, R.M., P.G., P.K.M., and M.G.; Methodology, R.M., P.G., P.K.M., and M.G.; Investigation, P.G., P.K.M., M.G., D.T.H., H.B., A.G., and S.D. ; Resources-

R.M.; Writing- original draft, R.M., P.K.M., and P.G.; Writing-review and editing, R.M., P.G., and P.K.M.,; Funding acquisition, R.M.; Supervision, R.M.

\section{ACKNOWLEDGEMENTS}

The authors would like to thank the Central Instrumentation facility, School of Life

Sciences for confocal microscope and Fluorescence Spectrophotometer.

\section{CONFLICT OF INTEREST}

The authors declare they have no conflict of interest.

\section{FUNDING}

R.M. was supported by grants from UGC (MRP-Major-BIOC-2013-24744), India and from DBT (BT/PR28600/BRB/10/1678/2018), India. P.G., P.K.M., M.G., and D.T.H. were supported by fellowship from CSIR. 


\section{FIGURE LEGENDS}

\section{Figure 1. Fun30 in C. albicans is a DNA-stimulated ATPase with fork DNA being the}

optimal effector. (A). Purification of recombinant $\Delta$ NFun30 from E. coli. (B). ATPase activity was performed as explained in Materials and Methods using different DNA effector molecules. The protein concentration was $200 \mathrm{nM}$ and the DNA concentration was $500 \mathrm{nM}$ in these experiments. The protein shows DNA-independent ATPase activity that is stimulated in the presence of Fork DNA. (C). The $\mathrm{K}_{\mathrm{M}}$ was calculated for Fork DNA by estimating ATPase activity in the presence of increasing concentration of DNA. The protein concentration was $200 \mathrm{nM}$ in this experiment. (D). Binding constant $\left(\mathrm{K}_{\mathrm{d}}\right)$ was calculated using fluorescence spectroscopy for the interaction of $\Delta$ NFun30 with DNA in the absence and presence of $60 \mu \mathrm{M}$ ATP. (E). Binding constant $\left(\mathrm{K}_{\mathrm{d}}\right)$ was calculated using fluorescence spectroscopy for the interaction of $\Delta \mathrm{NFun} 30$ with ATP in the absence and presence of $6 \mu \mathrm{M}$ Fork DNA. (F). Table depicting the $\mathrm{K}_{\mathrm{d}}$ values for the interaction of ATP and Fork DNA with $\Delta$ NFun30.

The $K_{d}$ and $K_{M}$ are expressed as average \pm s.d. of three independent experiments.

Figure 2. Fun30 regulates the expression of RTT109, SNF2, TEL1, and MEC1 in $C$.

albicans. (A). Expression of FUN30, RTT109, SNF2, TEL1, and MEC1 in FUN30mycHz was compared to the expression in FUN30myc strain using qPCR. (B). Expression of FUN30, RTT109, SNF2, TEL1, and MEC1 in analysed in BWP17-URA3, FUN3OHz-URA3, FUN30Hz/FUN30OE-URA3, and, FUN30Hz/RTT109OE-URA3 using qPCR. (C). Expression of RDN18, UBC13 and EFB1 was analysed by qPCR in FUN30myc and FUN30mycHz strain. (D). Expression of Fun30myc was analysed by western blot in FUN30myc and FUN30mycHz strains. G6PDH was used as internal control. (E). Expression of H3ac was analysed by western blot in FUN30myc and FUN3OmycHz strains. H3 was used as internal control. (F). The occupancy of Fun30myc on FUN30, RTT109, SNF2, TEL1, and 
MEC1 promoters was compared in FUN30myc and FUN30mycHz strains by ChIP. (G). The occupancy of H3ac on FUN30, RTT109, SNF2, TEL1, and MEC1 promoters was compared in FUN30myc and FUN30mycHz strains by ChIP. (H). The occupancy of Fun30myc on the intergenic regions of Chr5 and on GAPDH promoter was compared in FUN30myc and FUN3OmycHz strains by ChIP. (I). The occupancy of H3ac on the intergenic regions of Chr5 and on GAPDH promoter was compared in FUN30myc and FUN3OmycHz strains by ChIP. The qPCR and ChIP data are presented as average \pm s.e.m. of three biological replicates. Star indicates $\mathrm{p}<0.05$. The western blots were repeated for three biological replicates and one representative image is shown.

Figure 3. H3ac regulates the expression of FUN30, SNF2, TEL1, and MEC1. (A). Expression of RTT109, FUN30, SNF2, TEL1, and MEC1 were analysed in BWP17-URA3, RTT109D-URA3, RTT109D/RTT109OE-URA3, and RTT109D/FUN30OE-URA3 using qPCR. (B). Expression of RTT109, FUN30, SNF2, TEL1, and MEC1 were analysed in FUN30myc and RTT109D strains using qPCR. (C). Expression of H3ac was analysed by western blot in BWP17-URA3, RTT109D-URA3, RTT109D/RTT109OE-URA3 strains. H3 was used as internal control. (D). Expression of Fun30myc was analysed by western blot FUN30myc and RTT109D strains. G6PDH was used as internal control. (E). Occupancy of H3ac on FUN30, SNF2, TEL1, and MEC1 promoters was analysed using ChIP in BWP17URA3, RTT109D-URA3, RTT109D/RTT109OE-URA3 strains. (F). Occupancy of Fun30myc on FUN30, SNF2, TEL1, and MEC1 promoters was analysed using ChIP in FUN30myc and RTT109D strains. (G). Sensitivity of BWP17-URA3, RTT109D-URA3, RTT109D/RTT109OE-URA3, and RTT109D/FUN30OE-URA3 to genotoxic stress was observed using plate assays. (H). Expression of VPS75, RTT109, FUN30, SNF2, TEL1, and MECl was analysed in BWP17-URA3 and VPS75Hz-URA3 strains by qPCR. 
The qPCR and ChIP data are presented as average \pm s.e.m. of three biological replicates. Star indicates $\mathrm{p}<0.05$. The western blots were repeated for three biological replicates and one representative image is shown.

Figure 4. $\mathrm{RTT109Hz} / \mathrm{FUN30Hz}$ double mutant shows differential response to genotoxic stress. (A). Expression of FUN30, RTT109, SNF2, TEL1, MEC1, RAD9, MRC1, and RAD5 was evaluated in FUN30myc and RTT109Hz/FUN30mycHz strains using qPCR. (B). Expression of FUN30, RTT109, SNF2, TEL1, MEC1, RAD9, MRC1, and RAD5 was evaluated in BWP17 and $R T T 109 H z / F U N 30 H z$ strains using qPCR. (C). Expression of RDN18, UBC13, and EFB1 was analysed by qPCR in RTT109Hz/FUN3OmycHz strain. (D). Sensitivity of FUN30myc, RTT109Hz, FUN30Hz, and RTT109Hz/FUN30mycHz strains was studied in the presence of CPT $(100 \mu \mathrm{M}), \mathrm{H}_{2} \mathrm{O}_{2}(7.5 \mathrm{mM})$, and MMS (0.02\%). (E).

Sensitivity of BWP17, RTT109Hz, FUN30Hz, and RTT109Hz/FUN30Hz strains was studied in the presence of CPT $(100 \mu \mathrm{M}), \mathrm{H}_{2} \mathrm{O}_{2}(7.5 \mathrm{mM})$, and MMS $(0.02 \%)$.

The qPCR data is presented as average \pm s.e.m. of three biological replicates. Star indicates $p$ $<0.05$.

Plates were incubated at $30^{\circ} \mathrm{C}$ and imaged after $24 \mathrm{hrs}$.

Figure 5. Rtt109 and Fun30 co-regulate the transcription of genes involved in DNA damage response pathways. Expression of (A). FUN30; (B). RTT109; (C). SNF2; (D). TEL1; (E). MEC1; (F) RAD9; (G). MRC1; (H). RAD5 was analysed in FUN30myc and RTT109Hz/FUN30mycHz strains in the presence of $\mathrm{H}_{2} \mathrm{O}_{2}(7.5 \mathrm{mM})$, CPT $(100 \mu \mathrm{M})$ and MMS $(0.02 \%)$. The qPCR data is presented as average \pm s.e.m. of three biological replicates. Star indicates $\mathrm{p}<0.05$.

Figure 6. The response to DNA damage is regulated by the occupancy of Fun30 and H3ac on $R A D$ 9, MRC1, and $R A D 5$ genes. (A). The occupancy of Fun30myc was analysed on FUN30, RTT109, SNF2, TEL1, MEC1, RAD9, MRC1, and RAD5 in FUN30myc and 
RTT109Hz/FUN3OmycHz in untreated cells. (B). The occupancy of H3ac was analysed on FUN30, RTT109, SNF2, TEL1, MEC1, RAD9, MRC1, and RAD5 in FUN30myc and RTT109Hz/FUN30mycHz in untreated cells. (C). The occupancy of Fun30myc was analysed on FUN30, RTT109, SNF2, TEL1, MEC1, RAD9, MRC1, and RAD5 in FUN30myc and RTT109Hz/FUN3OmycHz in cells treated with $\mathrm{H}_{2} \mathrm{O}_{2}(7.5 \mathrm{mM})$. (D). The occupancy of $\mathrm{H} 3 \mathrm{ac}$ was analysed on FUN30, RTT109, SNF2, TEL1, MEC1, RAD9, MRC1, and RAD5 in FUN30myc and RTT109Hz/FUN3OmycHz in cells treated with $\mathrm{H}_{2} \mathrm{O}_{2}(7.5 \mathrm{mM})$. (E). The occupancy of Fun30myc was analysed on FUN30, RTT109, SNF2, TEL1, MEC1, RAD9, $M R C 1$, and RAD5 in FUN30myc and RTT109Hz/FUN3OmycHz in cells treated with CPT $(100 \mu \mathrm{M})$. (F). The occupancy of H3ac was analysed on FUN30, RTT109, SNF2, TEL1, MEC1, RAD9, MRC1, and RAD5 in FUN30myc and RTT109Hz/FUN3OmycHz in cells treated with CPT $(100 \mu \mathrm{M})$. (G). The occupancy of Fun30myc was analysed on FUN30, RTT109, SNF2, TEL1, MEC1, RAD9, MRC1, and RAD5 in FUN30myc and RTT109Hz/FUN30mycHz in cells treated with MMS $(0.02 \%)$. (H). The occupancy of H3ac was analysed on FUN30, RTT109, SNF2, TEL1, MEC1, RAD9, MRC1, and RAD5 in FUN30myc and RTT109Hz/FUN30mycHz in cells treated with MMS (0.02\%).

The data is presented as average \pm s.e.m. of three biological replicates. Star indicates $p$ $<0.05$.

Figure 7. $R A D 9$ deletion in $R T T 109 H z / F U N 30 H z$ rescues the resistance to MMS. (A). Expression of RAD5 and RAD9 was analysed in RTT109Hz/FUN3OHz-URA3, RTT109Hz/FUN30Hz/RAD5OE-URA3, and RTT109Hz/FUN3OHz/RAD9Hz-URA3 strains using qPCR. (B). Sensitivity of BWP17-URA3, RTT109Hz/FUN3OHz-URA3, RTT109Hz/FUN30Hz/RAD5OE-URA3, and RTT109Hz/FUN3OHz/RAD9Hz-URA3 to MMS $(0.02 \%)$ was evaluated using plate assays. (C). Growth curve of BWP17-URA3, RTT109Hz/FUN3OHz-URA3, RTT109Hz/FUN3OHz/RAD5OE-URA3, and 
bioRxiv preprint doi: https://doi.org/10.1101/2021.07.22.453354; this version posted July 22, 2021. The copyright holder for this preprint (which

was not certified by peer review) is the author/funder, who has granted bioRxiv a license to display the preprint in perpetuity. It is made available under aCC-BY-NC-ND 4.0 International license.

RTT109Hz/FUN30Hz/RAD9Hz-URA3 in the absence and presence of MMS (0.02\%). (D).

Table showing the duplication times of the wild type and mutant strains in the absence and presence of MMS. 


\section{Figure 2}

\section{A.}
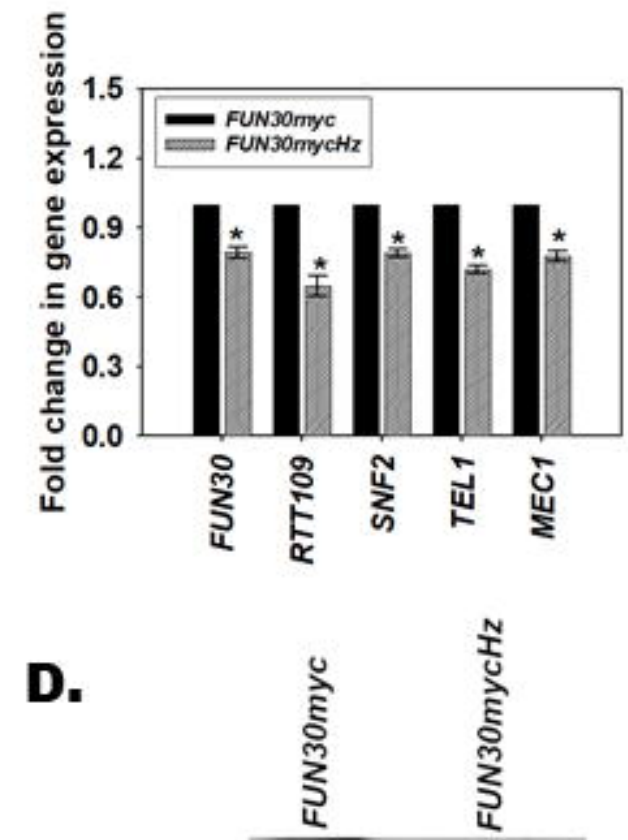

Fun30myc

142 kDa

G6PDH

$58 \mathrm{kDa}$

G.

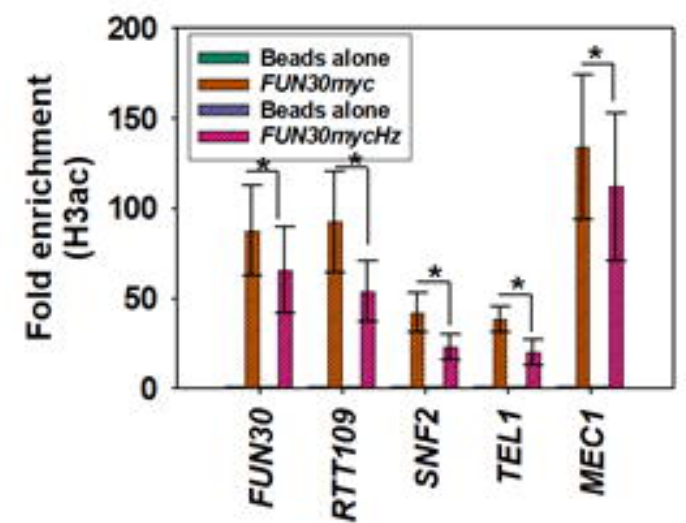

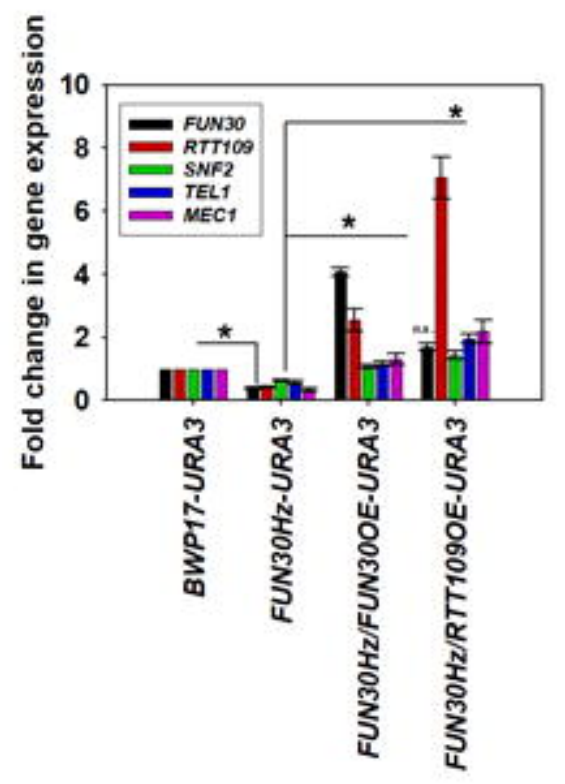

c.

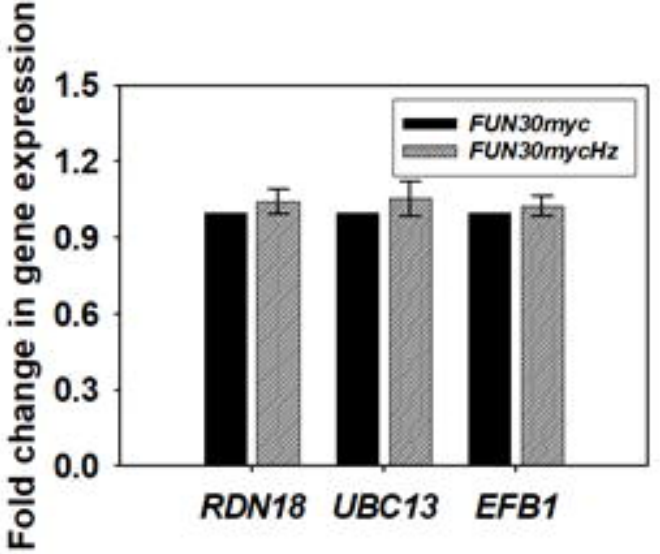

E.

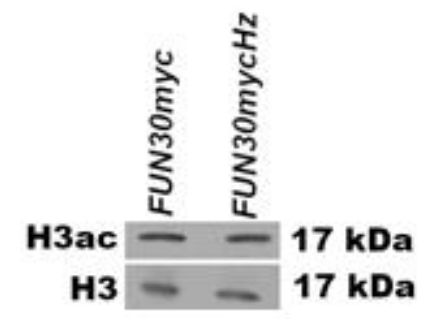

H.

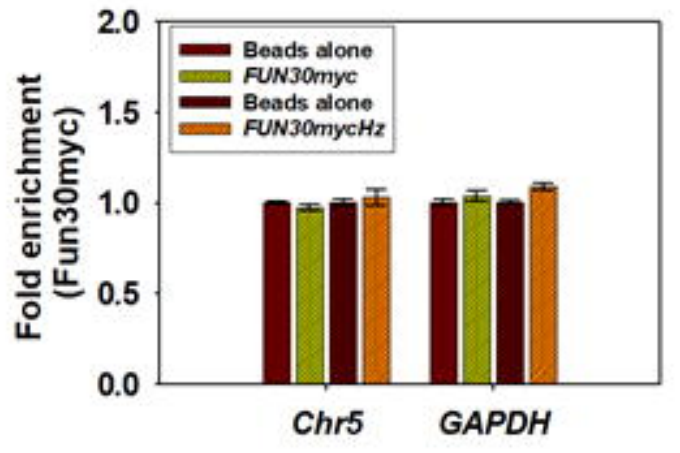

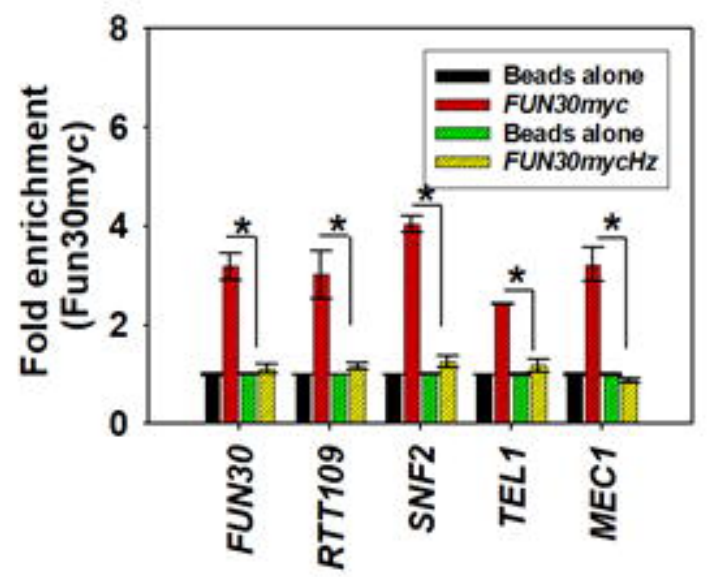

I.

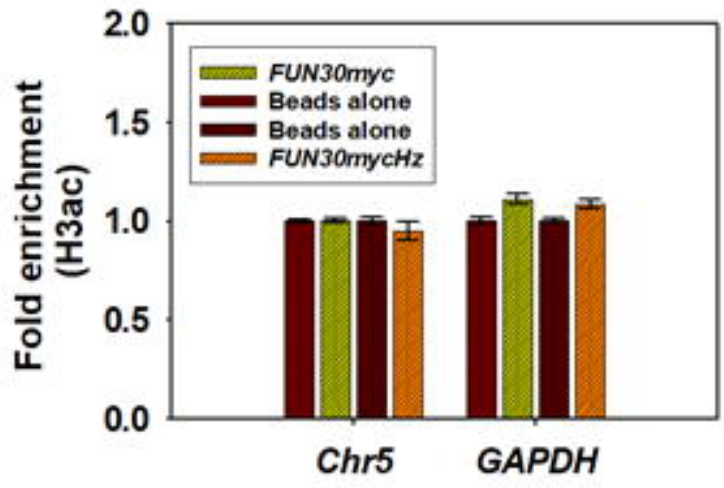


Figure 3
A.
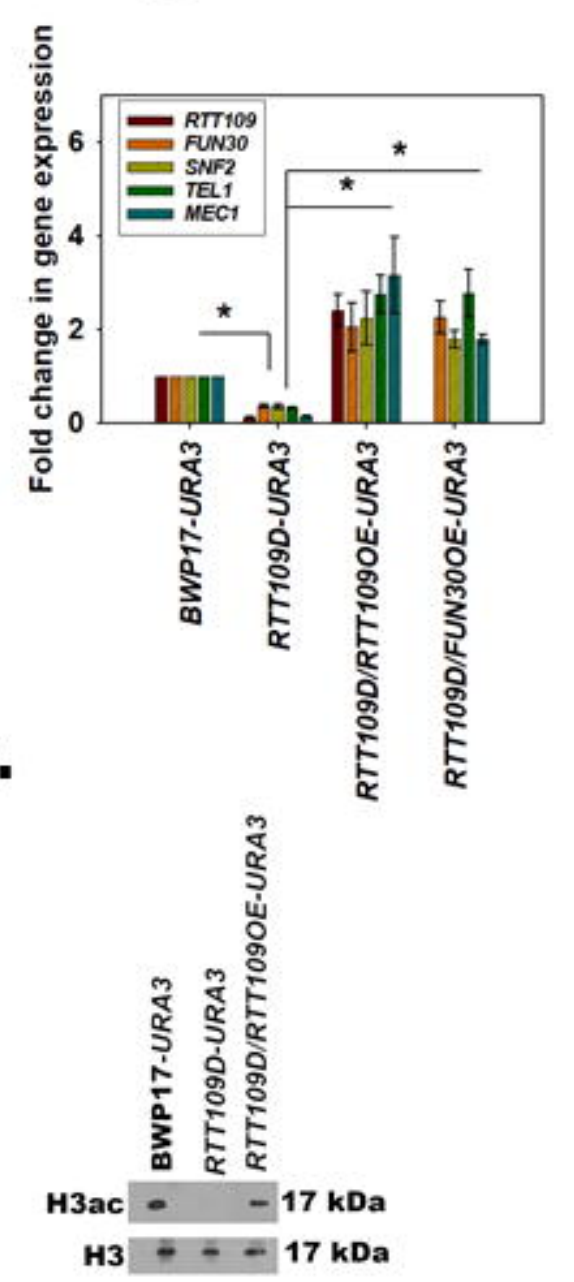

B.

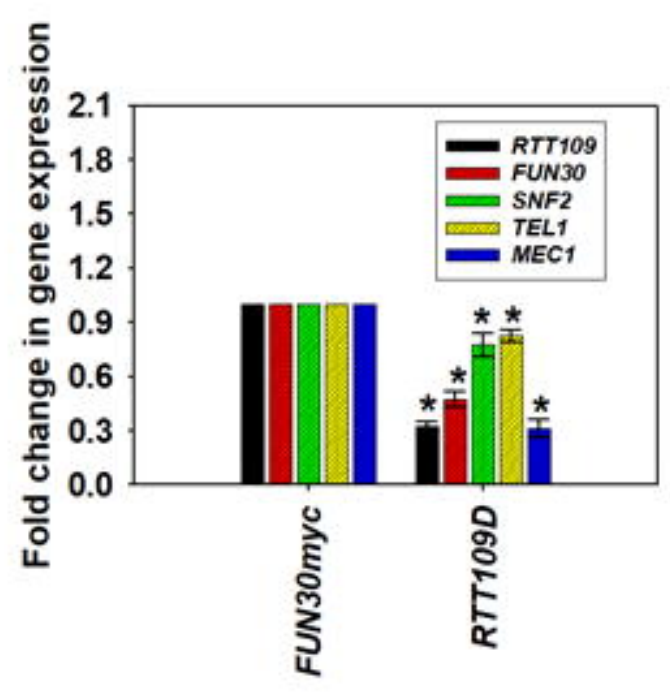

D.

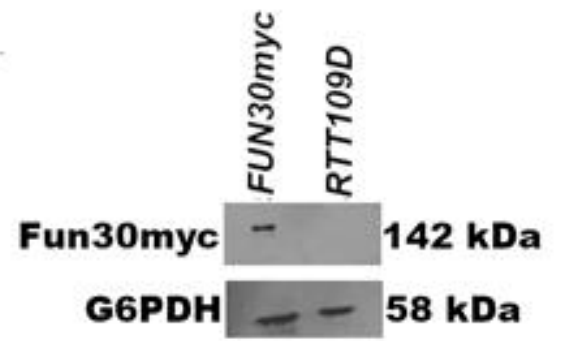

G.

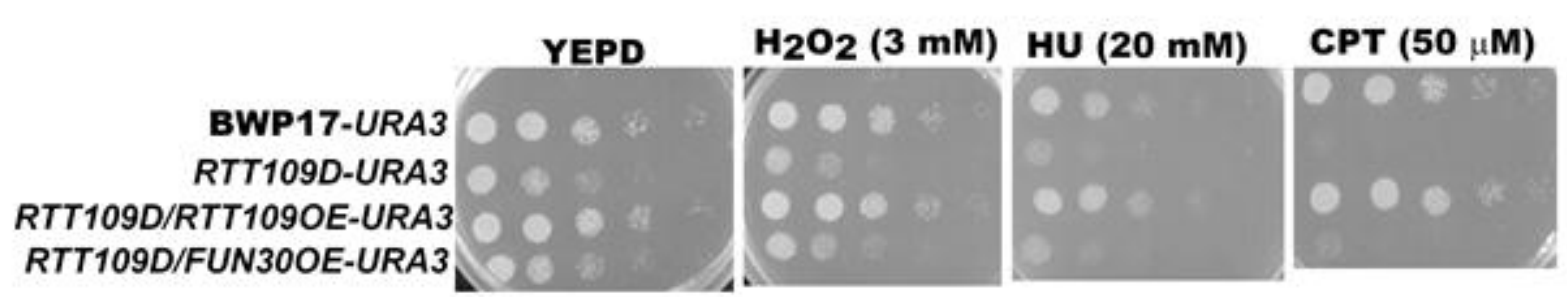

E.
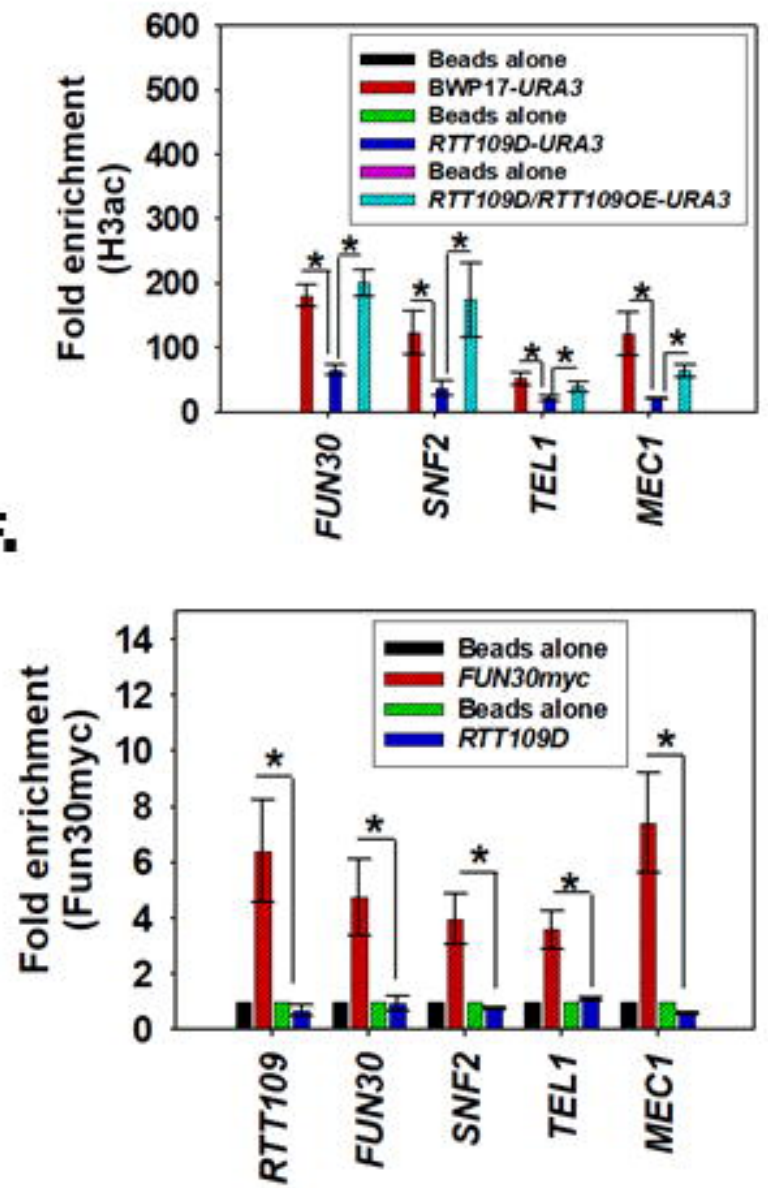

H.

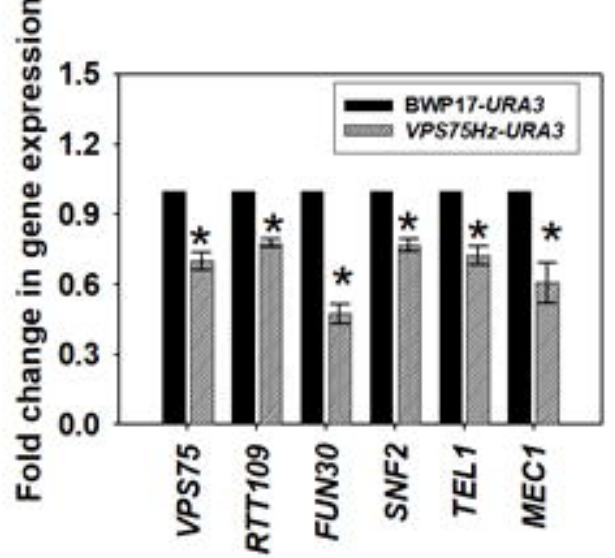


A.

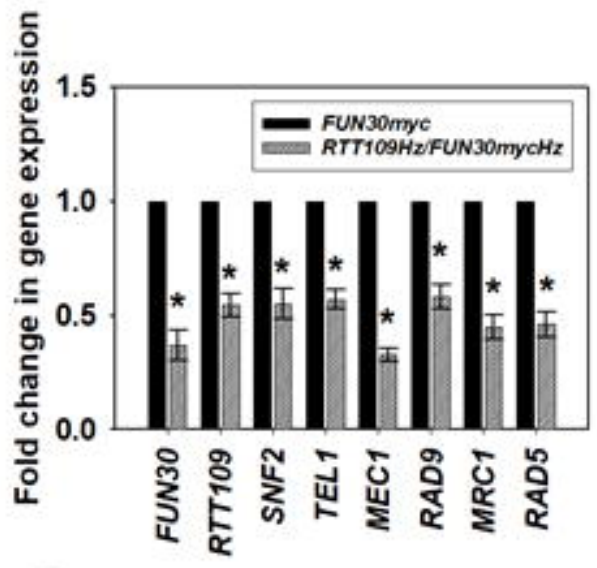

B.

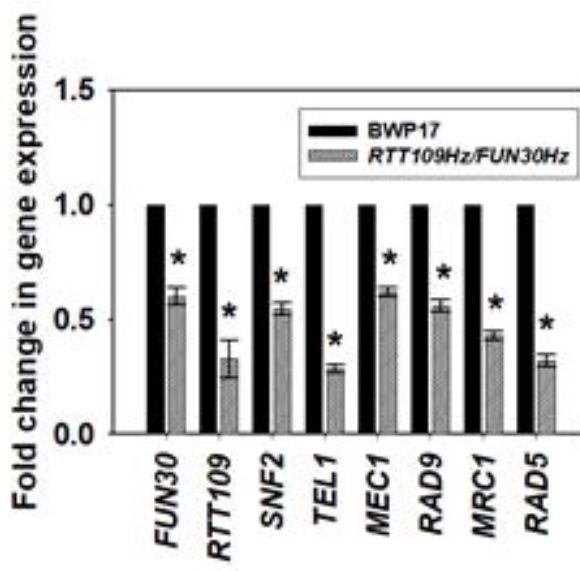

C.

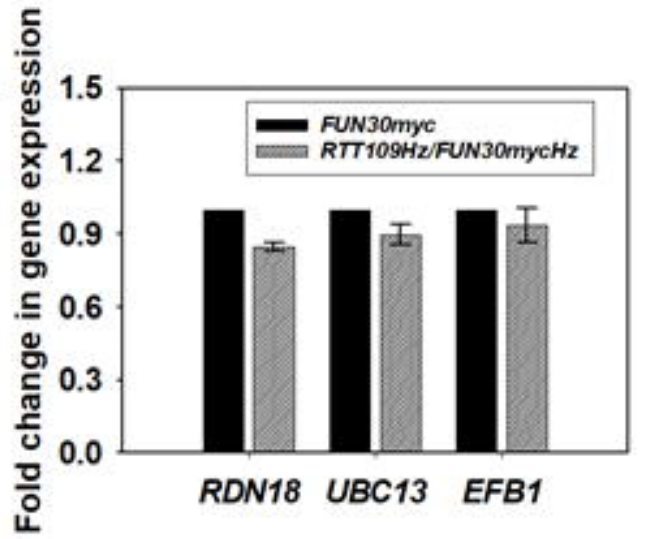

D.

\begin{tabular}{|c|c|}
\hline YEPD & СРТ $(100 \mu \mathrm{M})$ \\
\hline FUN30myc & $00=$ \\
\hline $\begin{array}{r}\text { FUN30mychz } \\
\text { RTT109Hz }\end{array}$ & 000 \\
\hline FUN30mychz OOO & 000 \\
\hline
\end{tabular}

FUN30myc YEPD $\mathrm{H}_{2} \mathrm{O} 2(7.5 \mathrm{mM})$ FUN30mycHz RTT109Hz RTT109Hz/FUN30mycHz

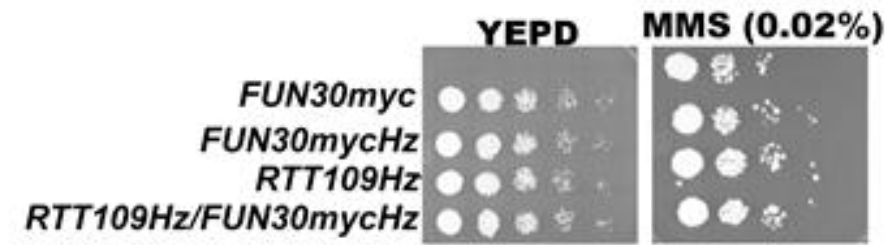

E.
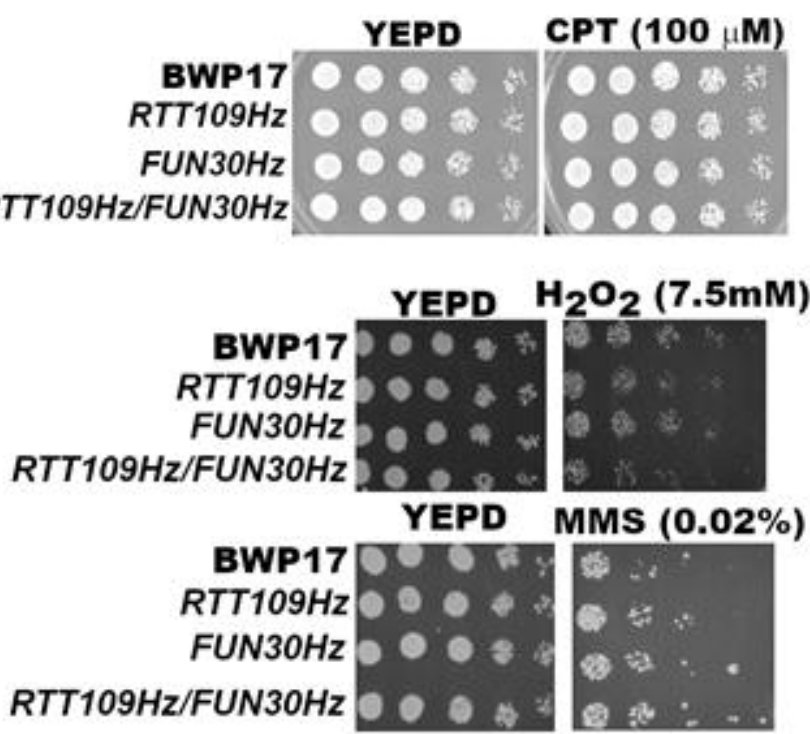
B.

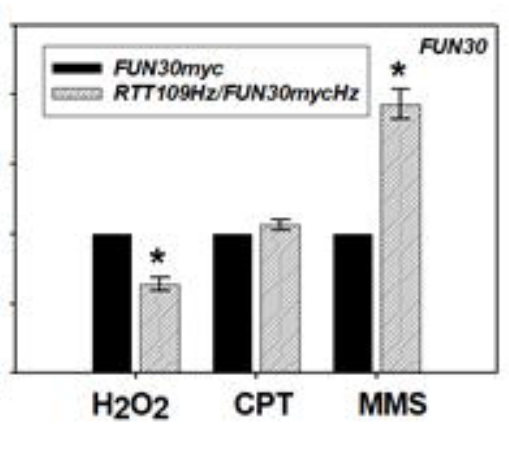

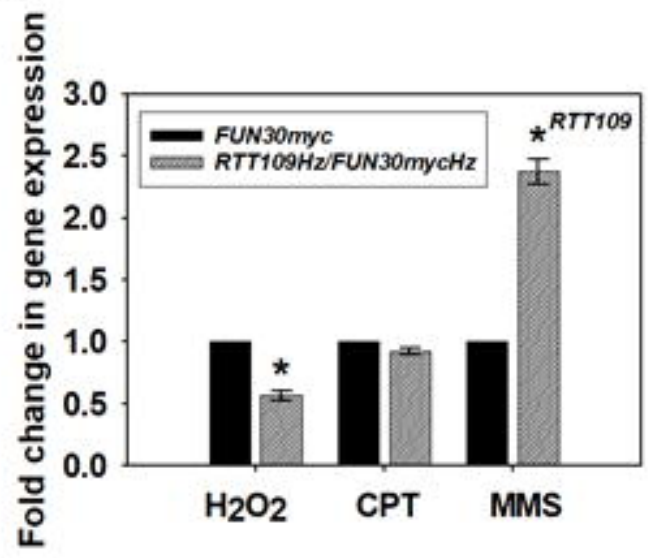

E.

D.

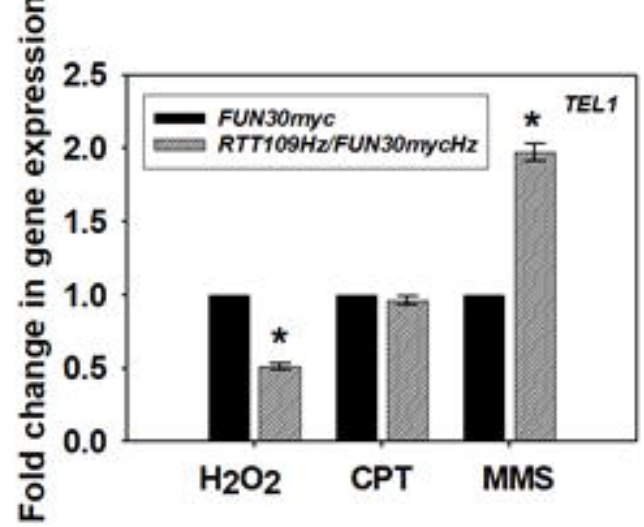

F.

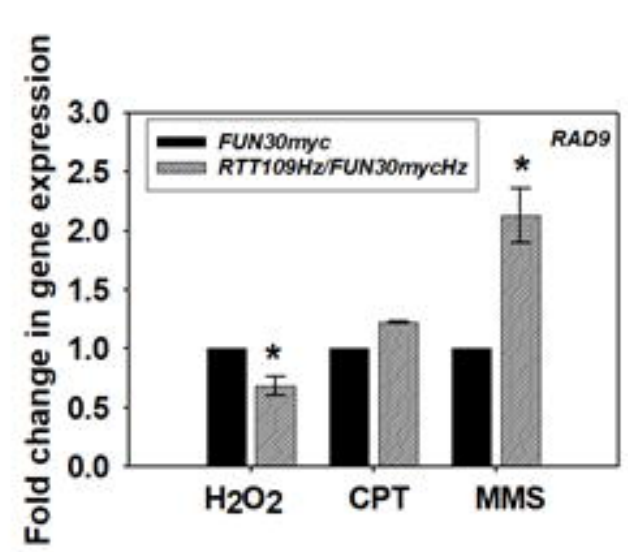

G.

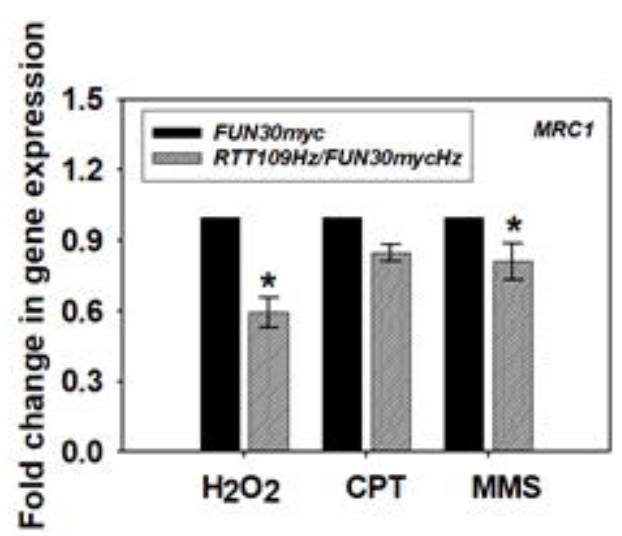

c.
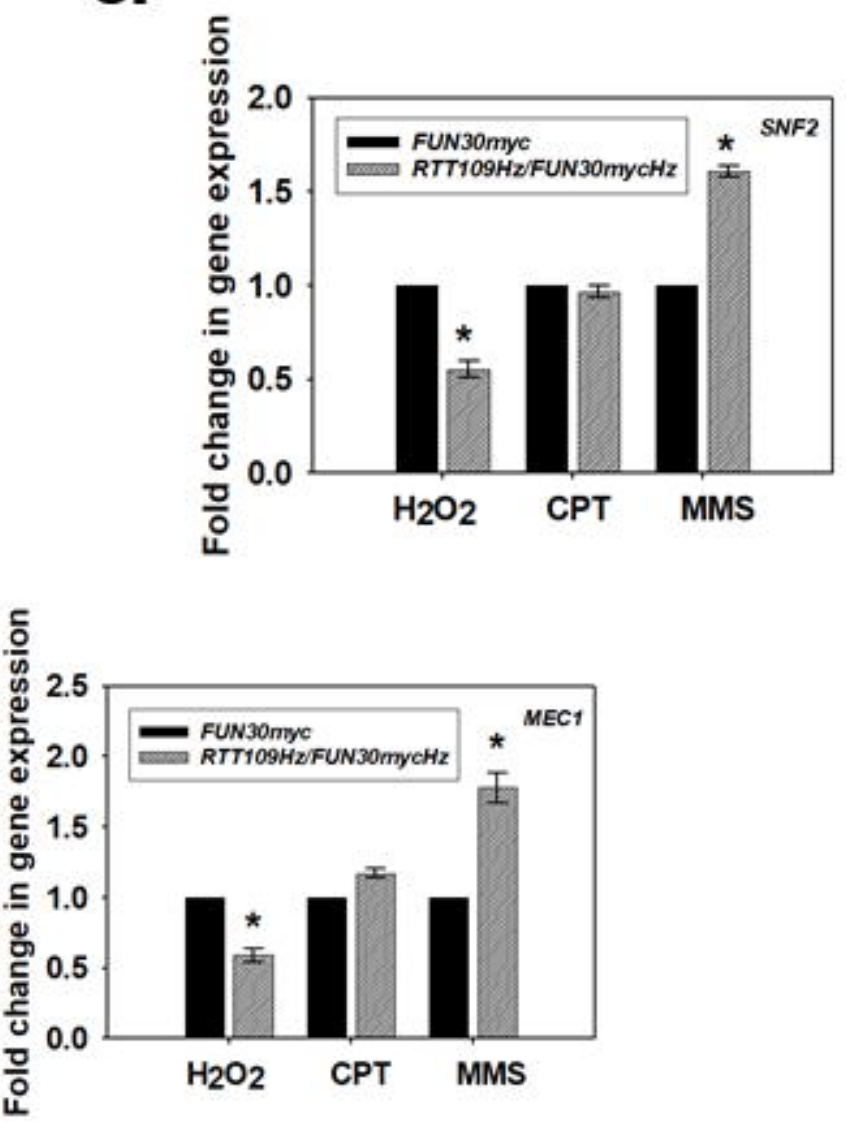

H.

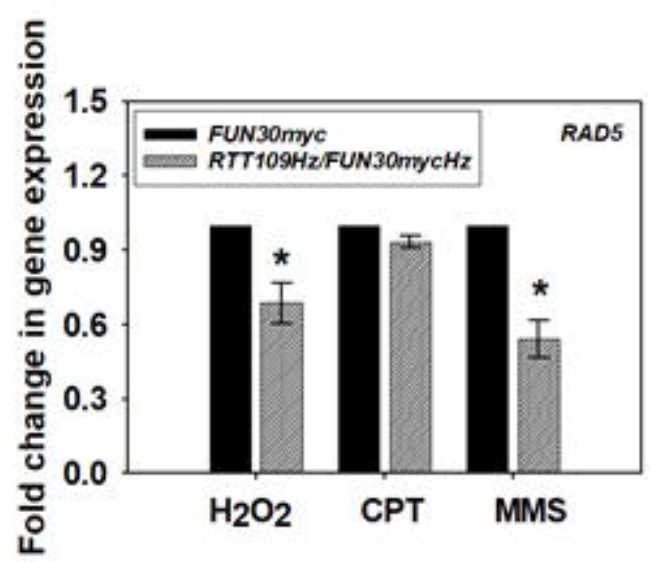



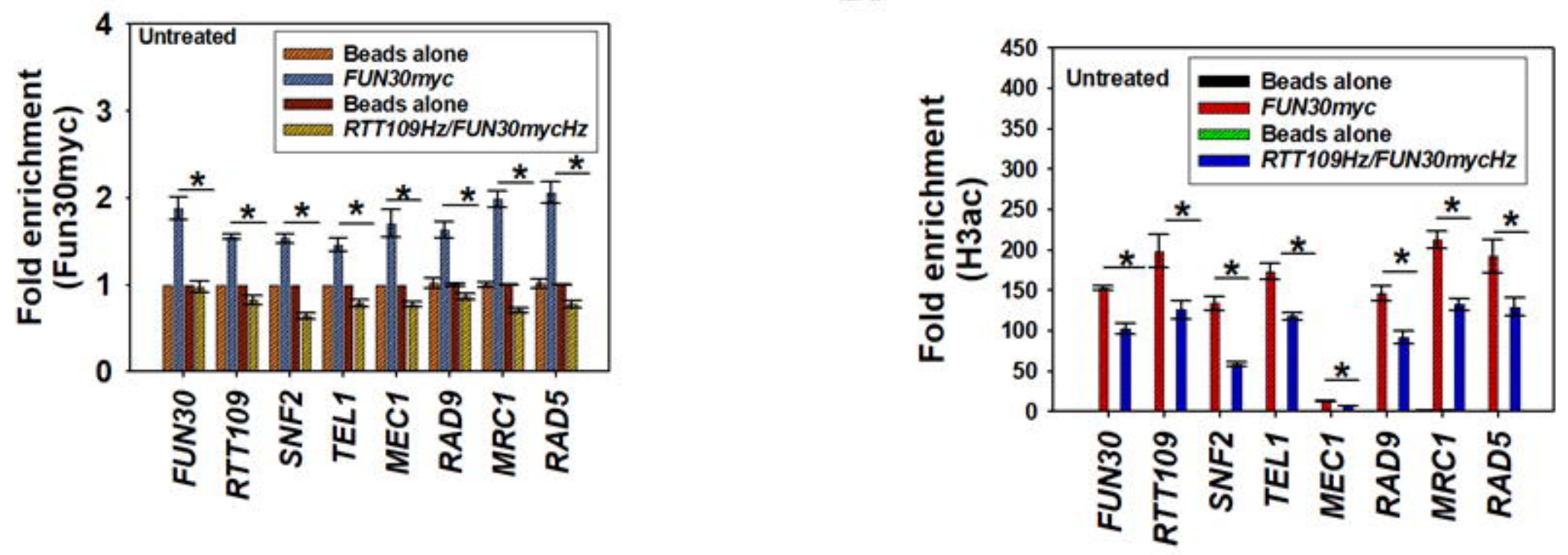

D.
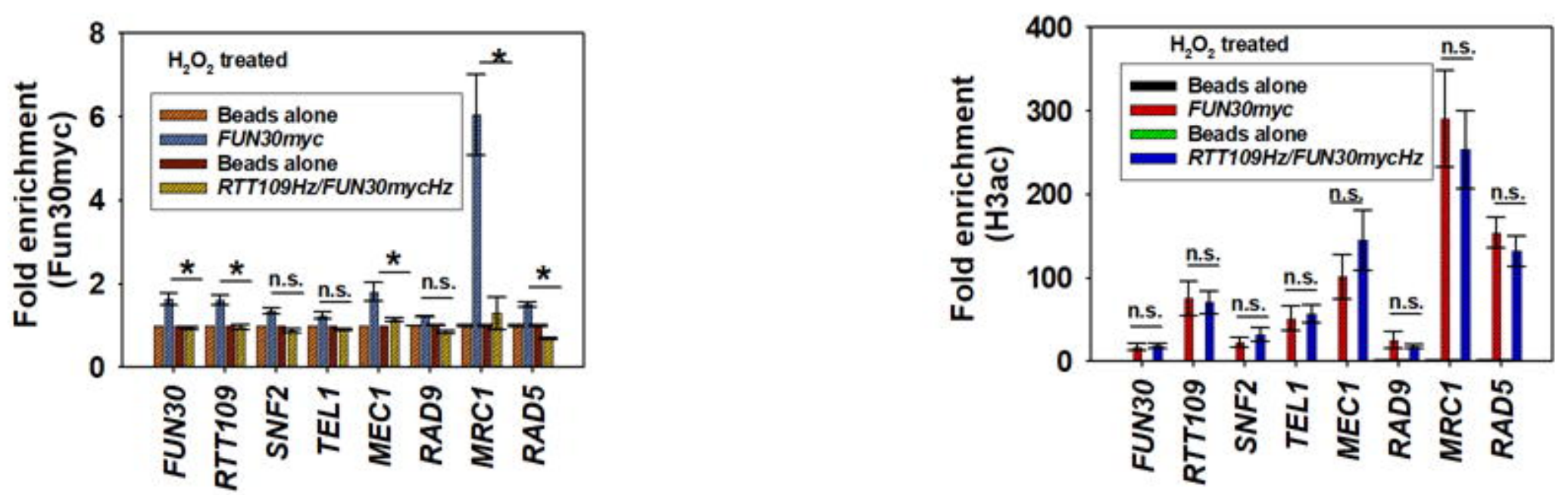
E.

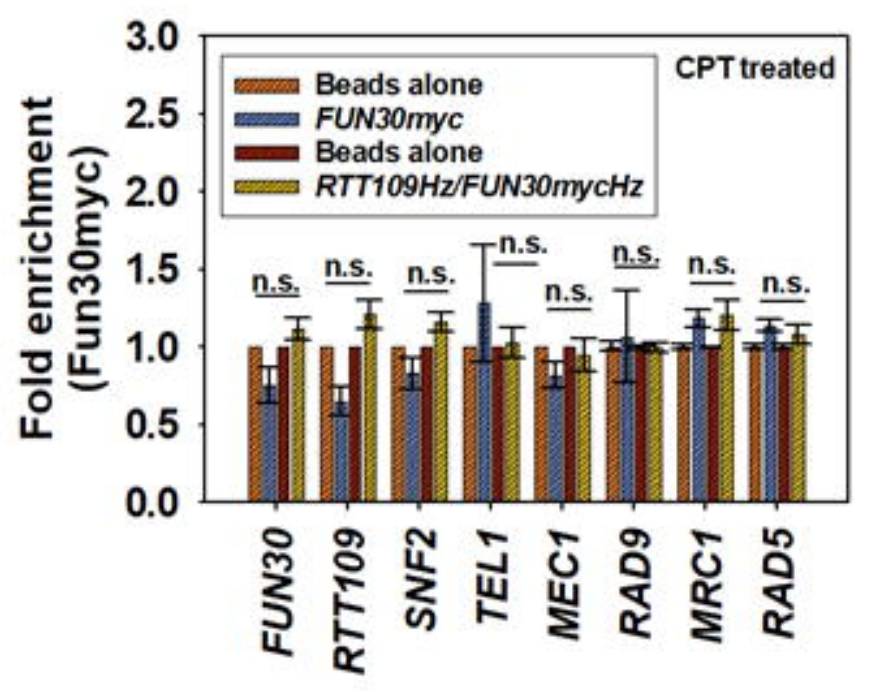

G.

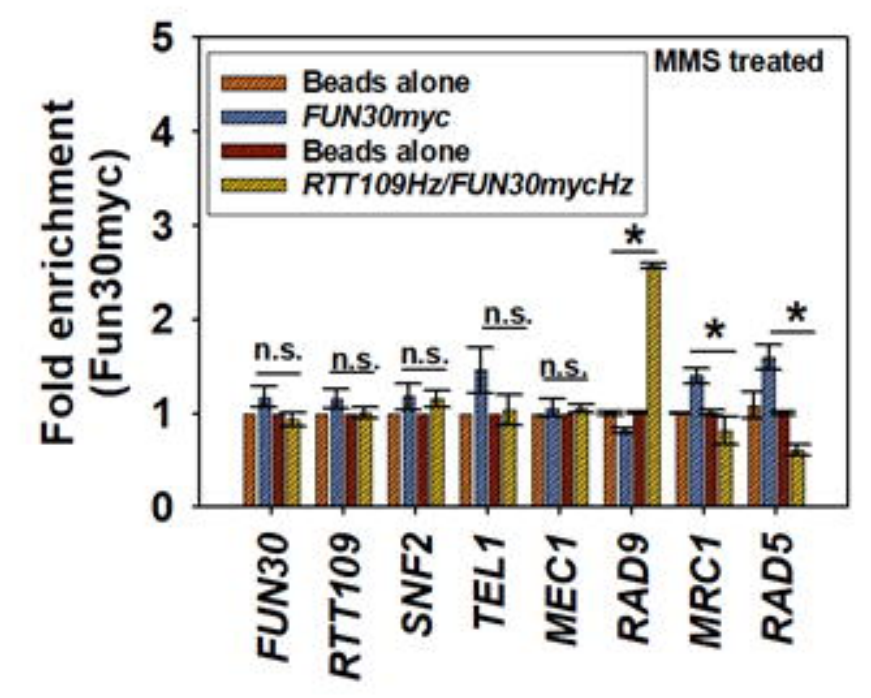

F.

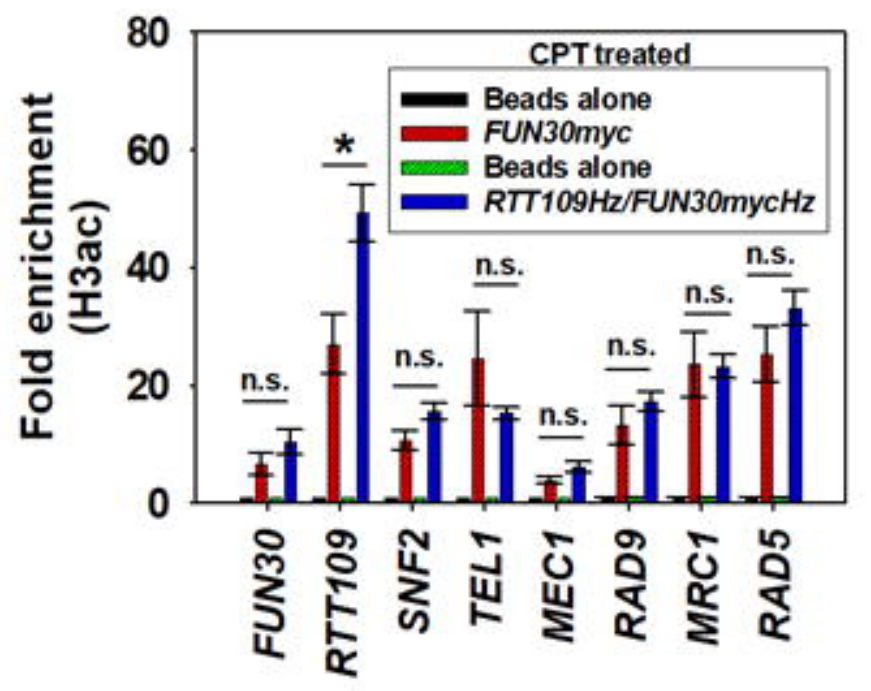

H.

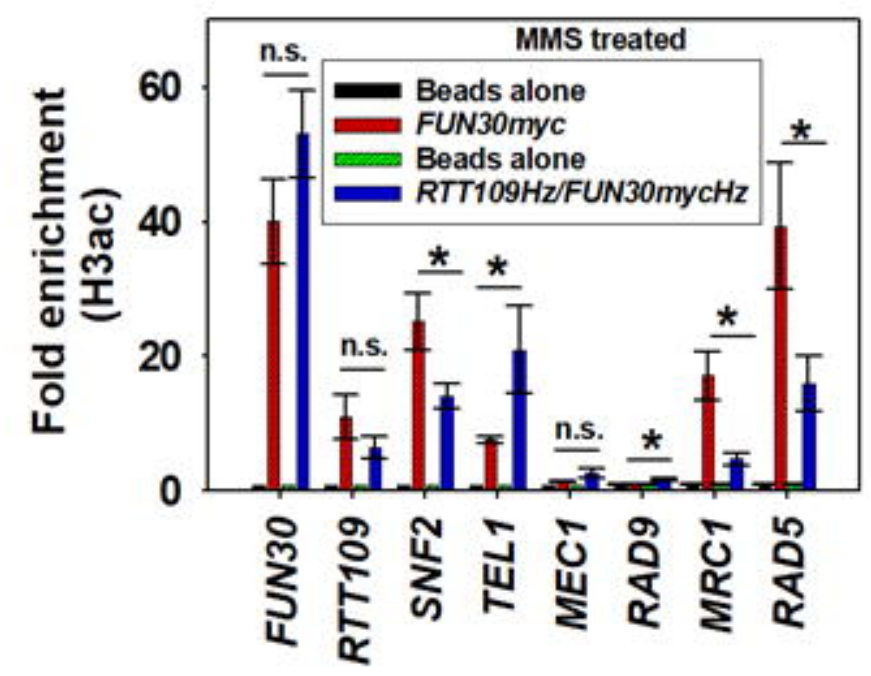


Figure 7

A.

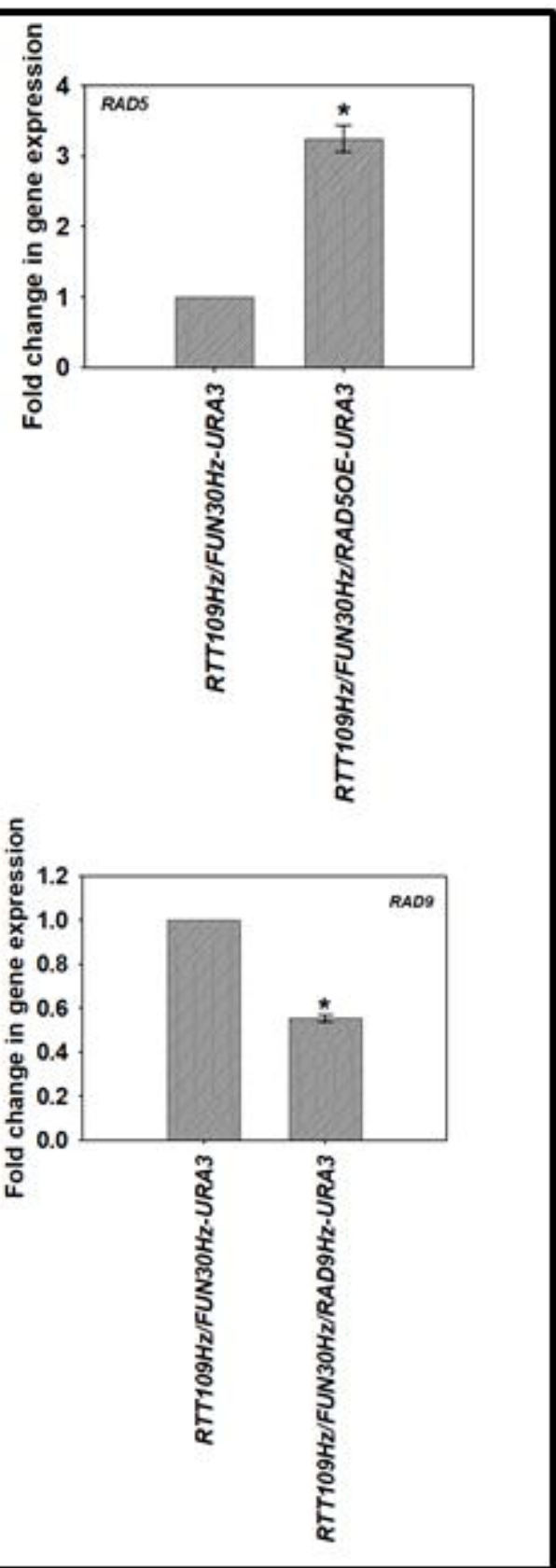

B.

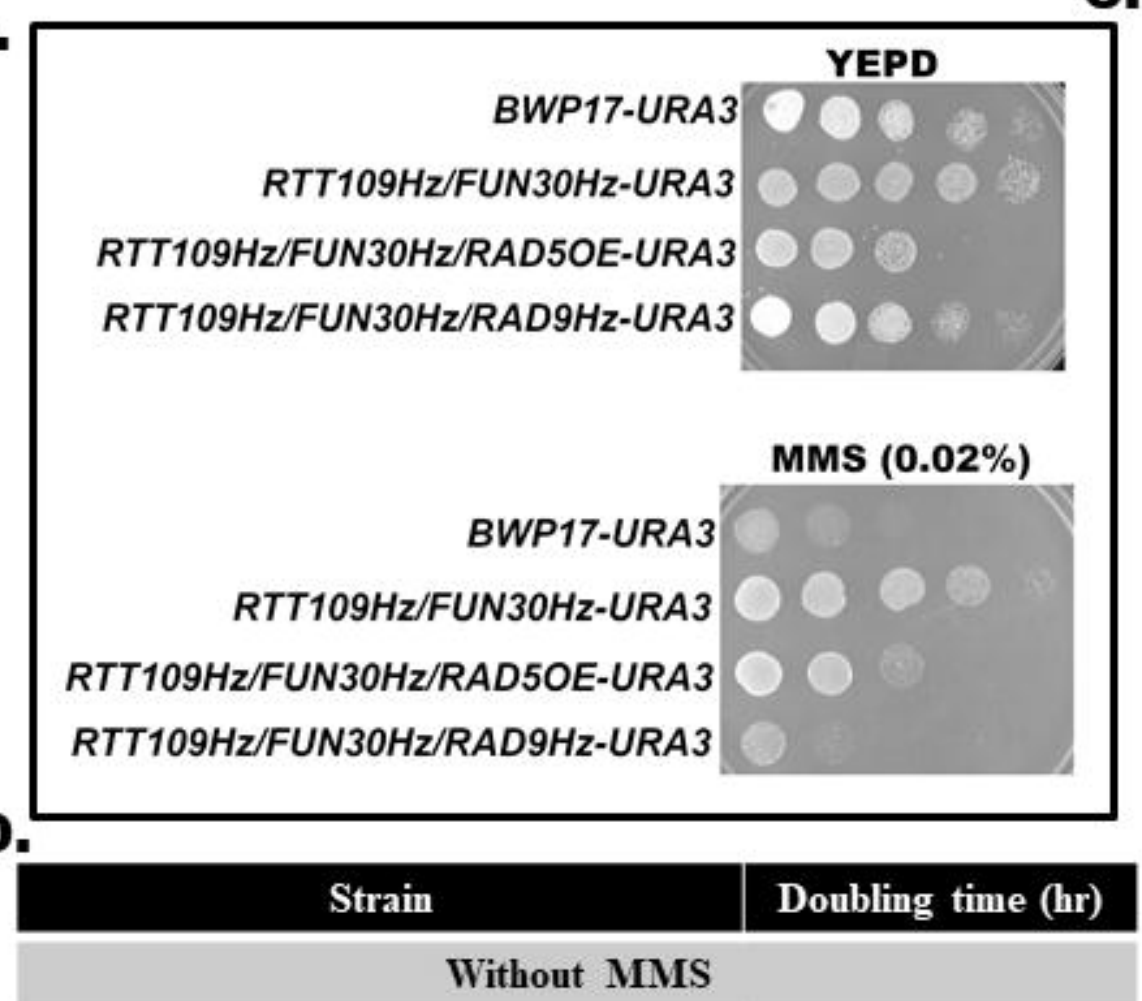

\begin{tabular}{|l|l|}
\hline BWP17-URA3 & $1.8 \pm 0.04$ \\
\hline RTT109Hz/FUN30Hz-URA3 & $2.4 \pm 0.004$ \\
\hline RTT2109Hz/FUN30Hz/RAD5OE-URA3 & $2.5 \pm 0.02$ \\
\hline RTT109Hz/FUN30Hz/RAD9Hz-URA3 & $1.8 \pm 0.02$ \\
\hline
\end{tabular}

With MMS

\begin{tabular}{|l|l|}
\hline BWP17-URA3 & $3.9 \pm 0.04$ \\
\hline RTT109Hz/FUN30Hz-URA3 & $2.4 \pm 0.09$ \\
\hline RTT2109Hz/FUN30Hz/RAD5OE-URA3 & $3.2 \pm 0.07$ \\
\hline RTT109Hz/FUN30Hz/RAD9Hz-URA3 & $3.8 \pm 0.02$ \\
\hline
\end{tabular}
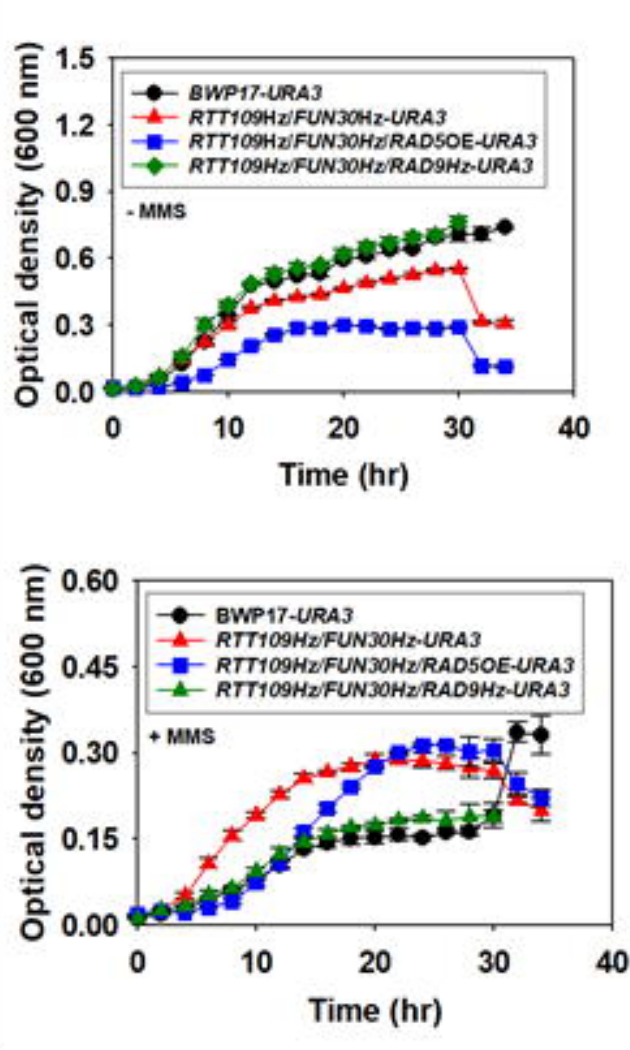